GAO Report to Congressional Committees

February 2005

$$
\begin{aligned}
& \text { ADULT DRUG } \\
& \text { COURTS }
\end{aligned}
$$

Evidence Indicates

Recidivism

Reductions and Mixed

Results for Other

Outcomes

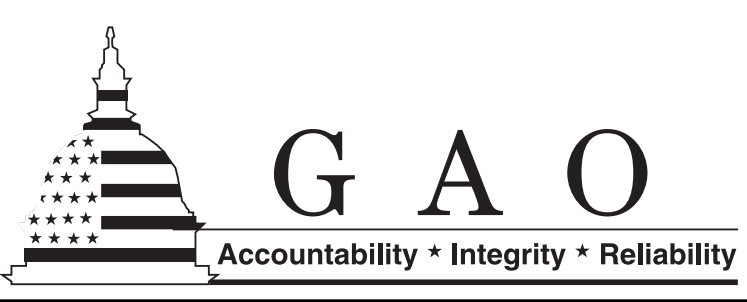




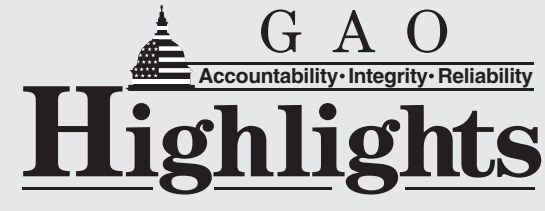

Highlights of GAO-05-219, a report to congressional committees

\section{Evidence Indicates Recidivism Reductions and Mixed Results for Other Outcomes}

\section{Why GAO Did This Study}

Drug court programs, which were established in the late 1980s as a local response to increasing numbers of drug-related cases and expanding jail and prison populations, have become popular nationwide in the criminal justice system. These programs are designed to reduce defendants' repeated crime (that is, recidivism), and substance abuse behavior by engaging them in a judicially monitored substance abuse treatment. However, determining whether drug court programs are effective at reducing recidivism and substance use has been challenging because of a large amount of weak empirical evidence.

The 21st Century Department of Justice Appropriations Authorization Act requires that GAO assess drug court program effectiveness. To meet this mandate, GAO conducted a systematic review of drug court program research, from which it selected 27 evaluations of 39 adult drug court programs that met its criteria for, among other things, methodological soundness. This report describes the results of that review of published evaluations of adult drug court programs, particularly relating to (1) recidivism outcomes, (2) substance use relapse, (3) program completion, and (4) the costs and benefits of drug court programs.

DOJ reviewed a draft of this report and had no comments. Office of National Drug Control Policy reviewed a draft of this report and generally agreed with the findings. www.gao.gov/cgi-bin/getrpt?GAO-05-219.

To view the full product, including the scope and methodology, click on the link above. For more information, contact Laurie $\mathrm{E}$. Ekstrand at (202) $512-8777$ or ekstrandl@gao.gov.

\section{What GAO Found}

Most of the adult drug court programs assessed in the evaluations GAO reviewed led to recidivism reductions during periods of time that generally corresponded to the length of the drug court program. GAO's analysis of evaluations reporting these data for 23 programs showed the following:

- Lower percentages of drug court program participants than comparison group members were rearrested or reconvicted.

- Program participants had fewer recidivism events than comparison group members.

- Recidivism reductions occurred for participants who had committed different types of offenses.

- There was inconclusive evidence that specific drug court components, such as the behavior of the judge or the amount of treatment received, affected participants' recidivism while in the program.

Recidivism reductions also occurred for some period of time after participants completed the drug court program in most of the programs reporting these data.

Evidence about the effectiveness of adult drug court programs in reducing participants' substance use relapse is limited to data available from eight drug court programs. Evaluations of these eight drug court programs reported mixed results on substance use relapse. For example, drug test results generally showed significant reductions in use during participation in the program, while self-reported results generally showed no significant reductions in use.

Completion rates, which refer to the percentage of individuals who successfully completed a program, in selected adult drug court programs ranged from 27 to 66 percent. Other than participants' compliance with drug court program procedures, no other program factor (such as the severity of the sanction that would be invoked if participants failed to complete the program) consistently predicted participants' program completion.

A limited number of evaluations-four evaluations of seven adult drug court programs - provided sufficient cost and benefit data to estimate their net benefits. Although the cost of six of these programs was greater than the costs to provide criminal justice services to the comparison group, all seven programs yielded positive net benefits, primarily from reductions in recidivism affecting judicial system costs and avoided costs to potential victims. Financial cost savings for the criminal justice system (taking into account recidivism reductions) were found in two of the seven programs.

\begin{tabular}{|c|c|c|c|}
\hline $\mathrm{Dr}$ & Drug court & Program evaluations & Findings \\
\hline $\int^{\text {offer }}$ & $\begin{array}{l}\text { program efforts } \\
\text { to reduce } \\
\text { recidivism }\end{array}$ & 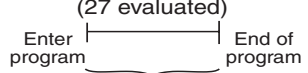 & $\begin{array}{l}\text { - Reduced recidivism while in program } \\
\text { - Evidence on drug use outcomes } \\
\text { limited because of few studies }\end{array}$ \\
\hline Justice system & $\begin{array}{l}\text { - Judicial } \\
\text { supervision } \\
\text { - Drug treatment } \\
\text { - Monitoring }\end{array}$ & $\begin{array}{l}\text { - Recidivism } \\
\text { - Drug use } \\
\text { - Program completion } \\
\text { - Costs of the program }\end{array}$ & $\begin{array}{l}\text { - Compliance related to completion } \\
\text { - Can have positive financial benefits }\end{array}$ \\
\hline
\end{tabular}




\section{Contents}

\section{Letter}

Background

Results

Concluding Observations

Agency Comments and Our Evaluation

Appendix I

Objectives, Scope, and Methodology

Appendix II

Evaluations Used Multiple Approaches to Assess Selection Bias

Comparison Groups Can Introduce the Problem of Selection Bias

Evaluations Addressed Selection Bias through Design

Evaluations Used a Variety of Statistical Methods to Minimize the Possible Effects of Selection Bias

\section{Appendix III}

\section{GAO Criteria for Assessing Evaluations of Drug Court} Programs' Cost-Benefit Analyses

The Evaluations We Reviewed and the Net Benefit Measure

Criteria for Assessing a Drug Court Program's Cost-Benefit Analysis

How the Drug Court Evaluations We Reviewed Used the Identified Cost-Benefit Principles

\section{Appendix IV}

Overview of Drug Court Program Characteristics and Participants

Drug Court Program Components

\section{Appendix V}

\section{Drug Court Programs Are Associated with Recidivism} Reductions

Drug Court Programs Led to Within-Program Recidivism

Reductions

Limited Evidence Indicates That Recidivism Reductions Endure 
Limited Evidence on Drug Court Programs' Impact on Substance Use Relapse

Evidence on Drug Court Programs' Impact on Substance Use Relapse Is Mixed

Appendix VII

Evidence Is Mixed about the Factors That Predict Program Completion

Program Completion Rates Vary

Program Completion Is Associated with Compliance with Program

Procedures

Effects of Drug Court Programs' Components on Program Completion Are Mixed

Participants Who Were Older and Had Less Criminal History than Other Participants Were Most Likely to Complete Programs

Evidence from Four Evaluations Indicates Drug Court Programs' Positive Net Benefits

Most Evaluations Found Drug Court Programs More Expensive than Conventional Case Processing

Drug Court Programs' Net Benefits Derived from Reductions in $\begin{array}{ll}\text { Recidivism } & 72\end{array}$

All Seven Drug Court Programs Reported Positive Net Benefits 73

Net Benefits May Underestimate the Programs' True Benefits

Appendix IX

GAO Contacts and Staff Acknowledgments

GAO Contacts

Acknowledgments

\section{Tables}

Table 1: Summary Information about Adult Drug Court Programs Included in GAO's Review

Table 2: The Eight Drug Court Program Evaluations in Our Cost-

Benefit Review 
Table 3: Research Designs, Comparison Groups, and Methods to Address Selection Bias for Evaluations GAO Used in Recidivism Analysis

Table 4: The Eight Drug Court Program Evaluations in Our CostBenefit Review

Table 5: Five Criteria for Assessing a Cost-Benefit Analysis of a Drug Court Program

Table 6: Summary of Criteria Applied in Eight Drug Court Program Evaluation Assessments

Table 7: Differences in Overall Rearrest Rates between Drug Court Program Participants and Comparison Group Members

Table 8: Differences in Reconviction Rates between Drug Court Program Participants and Comparison Group Members

Table 9: Differences in Rearrest and Reconviction Rates, over Longer Time Periods, between Drug Court Program Participants and Comparison Group Members

Table 10: Post-Program Differences in Recidivism in Six New York State Drug Court Programs

Table 11: Substance Use Relapse Results, by Different Measures of Use, for Programs GAO Reviewed

Table 12: Completion Rates for Selected Drug Court Programs Included in GAO's Review

Table 13: Reported Costs per Drug Court Program Participant in Four Evaluations

Table 14: Net Benefits per Participant in Seven Drug Court

Programs

\section{Abbreviations}

APD

GAO

ONDCP antisocial personality disorder Government Accountability Office Office of National Drug Control Policy

This is a work of the U.S. government and is not subject to copyright protection in the United States. It may be reproduced and distributed in its entirety without further permission from GAO. However, because this work may contain copyrighted images or other material, permission from the copyright holder may be necessary if you wish to reproduce this material separately. 
February 28, 2005

The Honorable Arlen Specter

Chairman

The Honorable Patrick J. Leahy

Ranking Minority Member

Committee on the Judiciary

United States Senate

The Honorable F. James Sensenbrenner, Jr.

Chairman

The Honorable John Conyers, Jr.

Ranking Minority Member

Committee on the Judiciary

House of Representatives

Drug court programs were established in the late 1980s as a local response to increasing numbers of drug-related cases and expanding jail and prison populations. These programs are designed to use a court's authority to reduce crime by changing defendants' substance abuse behavior. Under this concept, in exchange for the possibility of dismissed charges or reduced sentences, defendants are diverted to drug court programs in which they agree to participate in judicially monitored substance abuse treatment. Title II of the 21st Century Department of Justice Appropriations Authorization Act reauthorizes the award of federal grants for drug court programs that include court-supervised drug treatment. ${ }^{1}$ The award of federal grants to drug court programs was first authorized under Title V of the Violent Crime Control and Law Enforcement Act of $1994 .^{2}$

Drug court programs have become popular nationwide in the criminal justice system. As of September 2004, there were over 1,200 drug court programs operating in addition to about 500 being planned. With such expansion, it is important for policy and operational decision makers to have definitive information about drug court programs' effectiveness in

${ }^{1}$ Pub. L. No. 107-273, 116 Stat. 1758, 1795 (2002).

${ }^{2}$ Pub. L. No. 103-322. 
reducing recidivism and substance use relapse. ${ }^{3}$ In this respect, the 21 st Century Department of Justice Appropriations Authorization Act requires that we study drug court program effectiveness. ${ }^{4}$ In response, this report describes the results of published empirical evaluations of adult drug court programs, particularly relating to (1) recidivism outcomes of participants and other comparable offenders, (2) substance use relapse of participants and other comparable offenders, (3) program completion of participants, and (4) costs and benefits of drug court programs.

To address our objectives, we conducted a systematic review of drug court program literature. We identified 117 evaluations of adult drug court programs in the United States that were published between May 1997 and January 2004 and reported recidivism, substance use relapse, or program completion outcomes. Of these 117, we selected 27 evaluations that met additional criteria for methodological soundness. Most of the evaluations we selected used designs in which all drug court program participants were compared with an appropriate group of similar offenders who did not participate in the drug court program. In order to ensure that the groups are similar in virtually all respects aside from the intervention, we selected evaluations in which the comparison group was matched to the program group as closely as possible on a number of characteristics or that used statistical models to adjust, or control for, preexisting differences between the program and comparison groups. Five of the 27 evaluations were experiments in which participants were randomly assigned to groups. Random assignment works to ensure that the groups are comparable.

The 27 evaluations we selected for our review reported information on 39 unique adult drug court programs. We systematically collected information from these evaluations about the methodological characteristics of the evaluations, the participants and components of the drug court programs, the outcomes, and, where available, the costs of the drug court programs. To assess the methodological strength of the evaluations, we used generally accepted social science principles. Additionally, we used standard cost-benefit criteria to screen and assess the eight evaluations that reported cost and benefit information. Four of these contained sufficient data on costs and benefits to allow us to assess

\footnotetext{
${ }^{3}$ We use the term recidivism to refer generally to the act of committing new criminal offenses after having been arrested or convicted of a crime.

${ }^{4}$ Pub. L. No. 107-273, 116 Stat. 1758, 1799 (2002).
} 
net benefits. We selected the evaluations in our review according to the strength of their methodologies; therefore, our results cannot be generalized to all drug court programs or their evaluations. Finally, we interviewed drug court researchers and officials at the Department of Justice, the National Institute on Drug Abuse, and the Office of National Drug Control Policy (ONDCP). We conducted our work from October 2003 through February 2005 in accordance with generally accepted government auditing standards. Appendix I presents more details about our scope and methodology, including a list of the evaluations we reviewed. Appendix II describes the research designs and methods used in assessing recidivism in the evaluations we reviewed, and appendix III presents our criteria for assessing evaluations of drug court programs' cost-benefit analyses.

Of the 1,700 drug court programs operating or planned as of September 2004 , about 1,040 —nearly 770 operating and about 270 being plannedwere adult drug court programs, according to data collected by the Office of Justice Programs' Drug Court Clearinghouse and Technical Assistance Project. ${ }^{5}$ The primary purpose of these programs is to use a court's authority to reduce crime by changing defendants' substance abuse behavior. In exchange for the possibility of dismissed charges or reduced sentences, eligible defendants who agree to participate are diverted to drug court programs in various ways and at various stages in the judicial process. These programs are typically offered to defendants as an alternative to probation or short-term incarceration.

Drug court programs share several general characteristics but vary in their specific policies and procedures because of, among other things, differences in local jurisdictions and criminal justice system practices. In general, judges preside over drug court proceedings, which are called status hearings; monitor defendants' progress with mandatory drug testing; and prescribe sanctions and rewards as appropriate in collaboration with prosecutors, defense attorneys, treatment providers, and others. Drug court programs also vary in terms of the substance abuse treatment required. However, most programs offer a range of treatment options and generally require a minimum of about 1 year of participation before a defendant completes the program.

${ }^{5}$ The totals of adult drug court programs include tribal drug court programs, but exclude family drug court programs. 
In order to determine defendants' eligibility for participation, drug court programs typically screen defendants based on their legal status and substance use. The screening process and eligibility criteria can vary across drug court programs. ${ }^{6}$ According to the literature, eligible drug court program participants ranged from nonviolent offenders charged with drug-related offenses who have substance addictions to relatively mediumrisk defendants with fairly extensive criminal histories and failed prior substance abuse treatment experiences. Participants were also described as predominantly male with poor employment and educational achievements. Appendix IV presents additional information about the general characteristics of drug court programs and participants in the evaluations we reviewed.

Research on drug court programs has generally focused on program descriptions and process measures, such as program completion rates, and presented limited empirical evidence about the effectiveness of drug court programs in reducing recidivism and substance use. In 1997, we reported on 12 evaluations that met minimum research standards and concluded that the evaluations showed some positive results but did not firmly establish whether drug court programs were successful in reducing offender recidivism and substance use relapse. ${ }^{7}$ More recently, two syntheses of multiple drug court program evaluations have drawn positive conclusions about the impact of drug court programs. One synthesis concluded that criminal activity and substance use are reduced relative to other comparable offenders while participants are engaged in the drug court program, and that program completion rates ranged from 36 to 60 percent. ${ }^{8}$ Further, the other synthesis reported that drug offenders participating in a drug court program are less likely to re-offend than

\footnotetext{
${ }^{6}$ Criteria for legal eligibility can include the current offense, criminal justice histories, or supervision status (that is, whether the defendant is currently on probation). Criteria related to substance use can include frequency and type of current substance use, prior treatment experiences, or motivation to seek substance abuse treatment.

${ }^{7}$ GAO, Drug Courts: Overview of Growth, Characteristics, and Results, GAO/GGD-97-106 (Washington, D.C.: July 31, 1997).

${ }^{8}$ Belenko, S. Research on Drug Courts: A Critical Review 2001 Update. The National Center on Addiction and Substance Abuse at Columbia University, June 2001, p. 1. In his review, Belenko states that the reported program completion rates are consistent with findings in other studies.
} 
similar offenders sentenced to traditional correctional options, such as probation. ${ }^{9}$

Some of the evaluations included in these two syntheses had methodological limitations such as, the lack of strong comparison groups and the lack of appropriate statistical controls. Some did not use designs that compared all drug court program participants-including graduates, those still active, and dropouts-with similar nonparticipants. For example, they compared the outcomes of participants who completed the program with the outcomes of those who did not (that is, dropouts). These evaluations, upon finding that program graduates had better outcomes than dropouts, have concluded that drug court programs are effective. This is a likely overestimation of the positive effects of the intervention because the evaluation is comparing successes to failures, rather than all participants to nonparticipants. Additionally, other evaluations did not use appropriate statistical methods to adjust for preexisting differences between the program and comparison groups. Without these adjustments, variations in measured outcomes for each group may be a function of the preexisting differences between the groups, rather than the drug court program.

In most of the evaluations we reviewed, adult drug court programs led to recidivism reductions during periods of time that generally corresponded to the length of the drug court program - that is, within-program. ${ }^{10}$ Our analysis of evaluations reporting recidivism data for 23 programs showed that lower percentages of drug court program participants than comparison group members were rearrested or reconvicted. Program participants also had fewer incidents of rearrests or reconvictions and a longer time until rearrest or reconviction than comparison group members. These recidivism reductions were observed for any felony offense and for drug offenses, whether they were felonies or misdemeanors. However, we were unable to find conclusive evidence that specific drug court program components, such as the behavior of the judge, the amount of treatment received, the level of supervision provided, and the sanctions for not complying with program requirements, affect

\footnotetext{
${ }^{9}$ Wilson, D.B., O. Mitchell, and D.L. MacKenzie, A Systematic Review of Drug Court Effects on Recidivism, (forthcoming), p. 20.

${ }^{10} \mathrm{We}$ use within-program to refer to the period of time that all individuals who are enrolled are expected to be participating in the drug court program.
} 
participants' within-program recidivism. Post-program recidivism reductions were measured for up to 1 year after participants completed the drug court program in several evaluations, and in these the evidence suggests that the recidivism differences observed during the program endured. A more detailed description of the recidivism reduction results is included in appendix $\mathrm{V}$.

Evidence about the effectiveness of drug court programs in reducing participants' substance use relapse is limited and mixed. The evidence included in our review on substance use relapse outcomes is limited to data available from eight drug court programs. The data include drug test results and self-reported drug use; both measures were reported for some programs. Drug test results generally showed significant reductions in use during participation in the program, while self-reported results generally showed no significant reductions in use. Appendix VI presents additional information about the evaluations we reviewed that reported on substance use relapse outcomes.

Completion rates, which refer to the number of individuals who successfully completed a drug court program as a percentage of the total number admitted, in the programs we reviewed that assessed completion ranged from 27 to 66 percent. As might be expected, program completion was associated with participants' compliance with program requirements. Specifically, evaluations of 16 adult drug court programs that assessed completion found that participants' compliance with procedures was consistently associated with completion. These program procedures include attending treatment sessions, engaging in treatment early in the program, and appearing at status hearings. No other program factor, such as the severity of the sanction that would be invoked if participants failed to complete the program and the manner in which judges conducted status hearings, predicted participants' program completion. Several characteristics of the drug court program participants themselves were also associated with an increased likelihood of program completion. These characteristics include lower levels of prior involvement in the criminal justice system and age, as older participants were more likely to complete drug court programs than younger ones. Appendix VII presents additional information about the evaluations we reviewed that reported on program completion.

A limited number of evaluations in our review discussed the costs and benefits of adult drug court programs. Four evaluations of seven drug court programs provided sufficient cost and benefit data to estimate their net benefits (that is, the benefits minus costs). The cost per drug court 
program participant was greater than the cost per comparison group member in six of these drug court programs. However, all seven programs yielded positive net benefits, primarily from reductions in recidivism affecting both judicial system costs and avoided costs to potential victims. Net benefits ranged from about $\$ 1,000$ per participant to about $\$ 15,000$ in the seven programs. These benefits may underestimate drug court programs' true benefits because the evaluations did not include indirect benefits (such as reduced medical costs of treated participants). Financial cost savings for the criminal justice system (taking into account recidivism reductions) were found in two of the seven programs. We provide additional information about the reported costs and benefits of drug court programs we reviewed in appendix VIII.

\section{Concluding Observations}

Overall, positive findings from relatively rigorous evaluations in relation to recidivism, coupled with positive net benefit results, albeit from fewer studies, indicate that drug court programs can be an effective means to deal with some offenders. These programs appear to provide an opportunity for some individuals to take advantage of a structured program to help them reduce their criminal involvement and their substance abuse problems, as well as potentially provide a benefit to society in general.

Although not representative of all drug court programs, our review of 27 relatively rigorous evaluations provides evidence that drug court programs can reduce recidivism compared to criminal justice alternatives, such as probation. These results are consistent with those of past reviews of drug court evaluations. Positive results concerning recidivism are closely associated with program completion. Specifically, while drug court participation is generally associated with lower recidivism, the recidivism of program completers is lower than for participants in comparison or control groups. Thus, practices that encourage program completion may enhance the success of drug court programs in relation to recidivism.

While our review sheds little light on the specific aspects of these programs that are linked to positive recidivism outcomes, both participant compliance with drug court procedures and some participant characteristics seem to be related to success. To the extent that research can help to discern best practices for drug courts, the models for effective programs can be enhanced. Specifically, to the extent that drug court program managers can learn more about methods to retain participants for the duration of the program, they may be able to further enhance the positive impacts of drug court programs. 


\section{Agency Comments and Our Evaluation}

We requested comments on a draft of this report from the Attorney General and the Director of ONDCP. Department of Justice officials informed us that the agency had no comments on the report. ONDCP officials informed us that the agency generally concurred with our findings.

We are sending copies of this report to other interested congressional committees, the Attorney General, and the Director of the Office of National Drug Control Policy. We will also make copies available to others upon request. In addition, the report will be available at no charge on GAO's Web site at http://www.gao.gov.

If you or your staff have any questions concerning this report, please contact me at (202) 512-8777 or by e-mail at EkstrandL@gao.gov or William J. Sabol, Assistant Director, at (202) 512-3464, or SabolW@gao.gov. Key contributors to this report are listed in appendix IX.

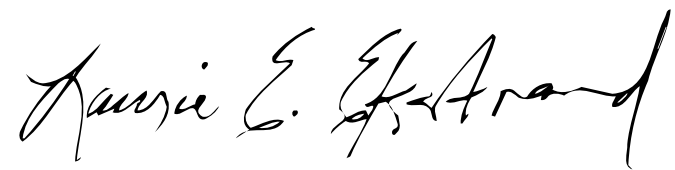

Laurie E. Ekstrand, Director Homeland Security and Justice Issues 


\section{Appendix I: Objectives, Scope, and Methodology}

The 21st Century Department of Justice Appropriations Authorization Act requires that we assess drug court program effectiveness. ${ }^{1}$ Our objectives were to assess the results of methodologically sound, published empirical evaluations of adult drug court programs, particularly relating to

(1) recidivism outcomes of participants and other comparable offenders,

(2) substance use relapse of participants and other comparable offenders,

(3) program completion of participants, and (4) costs and benefits of drug court programs.

To identify the universe of evaluations to include in our review, we used a three-stage process. First, we (1) conducted key-word searches of criminal justice and social science research databases; ${ }^{2}$ (2) searched drug court program-related Web sites, such as those of the National Drug Court Institute and the National Association of Drug Court Professionals; (3) reviewed bibliographies, published summaries, meta-analyses, and prior GAO reports on drug court programs; ${ }^{3}$ and (4) asked drug court researchers and officials in agencies that fund drug court research to identify evaluations. Our literary search identified over 230 documents, which consisted of published and unpublished outcome evaluations, process evaluations that described program objectives and operations, manuals and guides related to drug court program operations, commentary from drug court practitioners, and summaries of multiple program evaluations. Next, we reviewed these documents and identified 117 evaluations of adult drug court programs in the United States that (1) were published between May 1997 and January 2004 ${ }^{4}$ and (2) reported recidivism, substance use relapse, or program completion outcomes.

Finally, to select the evaluations we used in our in-depth review, we screened them to determine whether they met additional criteria for

\footnotetext{
${ }^{1}$ Pub. L. No. 107-273, 116 Stat. 1758, 1799 (2002).

${ }^{2}$ We searched the ERIC, Biosis Previews, Social Scisearch, National Criminal Justice Reference Service, Dissertation Abstracts Online, Gale Group Magazine Database, Wilson Social Science Abstracts, Gale Group Trade \& Industry Database, Gale Group Health \& Wellness Database, Gale Group Legal Resources Index, and Periodicals Abstracts PlusText.

${ }^{3}$ GAO, Drug Courts: Information on a New Approach to Address Drug-Related Crime, GAO/GGD-95-159BR (Washington, D.C.: May 22, 1995); GAO, Drug Courts: Overview of Growth, Characteristics, and Results, GAO/GGD-97-106 (Washington, D.C.: July 31, 1997); and GAO, Drug Courts: Better DOJ Data Collection and Evaluation Efforts Needed to Measure Impact of Drug Court Programs, GAO-02-434 (Washington, D.C.: April 18, 2002).

${ }^{4}$ In our last report that assessed the published research, GAO/GGD-97-106, we completed our review in May 1997.
} 
methodological soundness. Specifically, to assess recidivism and substance use relapse, we selected evaluations that used either an experimental design in which (1) eligible offenders were randomly assigned to different programs or conditions and (2) there was an acceptable level of attrition ${ }^{5}$ or a quasi-experimental design in which (1) all drug court program participants were compared with an appropriate group of comparable offenders who did not participate in the drug court program, and (2) appropriate statistical methods were used to adjust, or control, for group differences. If random assignment was not used, in an attempt to ensure that the groups were similar, aside from program participation (the intervention), the comparison group(s) should have been as alike as possible on a range of important characteristics. Statistical analyses can be used to further minimize differences between the program and comparison groups. Typically, statistical analyses to control for differences such as these are not necessary when study participants are randomly assigned to groups.

To assess program completion, we also selected evaluations that compared the outcomes of participants (such as program graduates and those who dropped out) within a drug court program in order to determine what factors, if any, are associated with program completion. We selected those evaluations that used appropriate statistical methods to control for differences between the participant groups. Of the 117 evaluations we screened, we selected 27 evaluations for our in-depth review.

The 27 evaluations we selected for our review reported information on 39 unique adult drug court programs that were implemented between 1991 and 1999. Table 1 lists the drug court program evaluated, researchers, and outcomes we used in our assessment of drug court program effectiveness. All of the evaluations we reviewed, as well as others consulted, is included in the bibliography.

\footnotetext{
${ }^{5}$ Over time, participants in an evaluation can drop out for various reasons. Acceptable levels of attrition can vary depending on other characteristics of the evaluation design, such as the sample size, the time frames covered, and statistical methods used.
} 
Table 1: Summary Information about Adult Drug Court Programs Included in GAO's Review

\begin{tabular}{|c|c|c|c|}
\hline \multirow[b]{2}{*}{ Drug court program evaluated (researcher) } & \multicolumn{3}{|c|}{ Outcomes used in our assessment } \\
\hline & Recidivism & Drug use & $\begin{array}{l}\text { Program } \\
\text { completion }\end{array}$ \\
\hline $\begin{array}{l}\text { Bakersfield (Calif.) Municipal Drug Court } \\
\text { (Anspach and Ferguson, 2003) }\end{array}$ & & & Yes \\
\hline \multicolumn{4}{|l|}{ Baltimore City (Md.) Drug Treatment Court } \\
\hline (Banks and Gottfredson, 2003) & Yes & & \\
\hline $\begin{array}{l}\text { (Gottfredson and Exum, 2002; Gottfredson, Najaka, and } \\
\text { Kearley, 2003) }\end{array}$ & Yes & & \\
\hline $\begin{array}{l}\text { Breaking the Cycle Program, }{ }^{a} \text { Birmingham, Ala. } \\
\text { (Harrell and others, 2003) }\end{array}$ & Yes & Yes & \\
\hline $\begin{array}{l}\text { Breaking the Cycle Program, }{ }^{\text {a }} \text { Jacksonville, Fla. } \\
\text { (Harrell and others, 2003) }\end{array}$ & Yes & Yes & \\
\hline $\begin{array}{l}\text { Breaking the Cycle Program, }{ }^{a} \text { Tacoma, Wash } \\
\text { (Harrell and others, 2003) }\end{array}$ & Yes & Yes & \\
\hline $\begin{array}{l}\text { Bronx (N.Y.) Treatment Court } \\
\text { (Rempel and others, 2003) }\end{array}$ & Yes & & Yes \\
\hline \multicolumn{4}{|l|}{ Brooklyn (N.Y.) Treatment Court } \\
\hline (Rempel and DeStefano, 2001) & & & Yes \\
\hline (Rempel and others, 2003) & Yes & & Yes \\
\hline \multicolumn{4}{|l|}{ Broward County (Fla.) Drug Court } \\
\hline (Schiff and Terry, 1997) & & & Yes \\
\hline (Senjo and Leip, 2001) & & & Yes \\
\hline $\begin{array}{l}\text { Chester County (Penn.) Drug Court Program } \\
\text { (Brewster, 2001) }\end{array}$ & Yes & Yes & \\
\hline \multicolumn{4}{|l|}{ Clark County Drug Court (Las Vegas, Nev.) } \\
\hline (Goldkamp, White, and Robinson, 2001) & & & Yes \\
\hline (Miethe, Lu, and Reese, 2000) & Yes & & \\
\hline $\begin{array}{l}\text { Creek County (Okla.) Drug Court } \\
\text { (Anspach and Ferguson, 2003) }\end{array}$ & & & Yes \\
\hline $\begin{array}{l}\text { D.C. Superior Court Drug Intervention Program } \\
\text { (Harrell, Cavanagh, and Roman, 1998) }\end{array}$ & Yes & Yes & \\
\hline $\begin{array}{l}\text { Douglas County (Neb.) Drug Court } \\
\text { (Spohn and others, 2001; Martin, Spohn, Piper, and } \\
\text { Frenzel-Davis, 2001) }\end{array}$ & Yes & & \\
\hline \multicolumn{4}{|l|}{ Escambia County (Fla.) Drug Court } \\
\hline (Peters and Murrin, 2000) & & & Yes \\
\hline (Peters, Haas, and Murrin, 1999) & & & Yes \\
\hline (Truitt and others, 2002) & Yes & & Yes \\
\hline
\end{tabular}




\begin{tabular}{|c|c|c|c|}
\hline \multirow[b]{2}{*}{ Drug court program evaluated (researcher) } & \multicolumn{3}{|c|}{ Outcomes used in our assessment } \\
\hline & Recidivism & Drug use & $\begin{array}{l}\text { Program } \\
\text { completion }\end{array}$ \\
\hline $\begin{array}{l}\text { Hamilton County Drug Court (Cincinnati, Ohio) } \\
\text { (Listwan and others, 2003) }\end{array}$ & $\mathrm{Yes}^{\mathrm{b}}$ & & \\
\hline \multicolumn{4}{|l|}{ Jackson County (Mo.) Drug Court } \\
\hline (Anspach and Ferguson, 2003) & & & Yes \\
\hline (Truitt and others, 2002) & Yes & & Yes \\
\hline $\begin{array}{l}\text { Kentucky Drug Court Programs } \\
\text { (Logan, Hoyt, and Leukefeld, 2001) }\end{array}$ & Yes & & \\
\hline $\begin{array}{l}\text { Las Cruces (N. Mex.) Municipal DWI Drug Court } \\
\text { (Breckenridge and others, 2000) }\end{array}$ & Yes $^{d}$ & & \\
\hline $\begin{array}{l}\text { Los Angeles County (Calif.) Drug Court Program } \\
\text { (Deschenes and others, 1999; Fielding and others, 2002) }\end{array}$ & Yes & & \\
\hline $\begin{array}{l}\text { Maricopa County (Ariz.) First Time Drug Offender Program } \\
\text { (Deschenes, and others, 1996; Turner and others, 1999) }\end{array}$ & Yes & Yes & \\
\hline \multicolumn{4}{|l|}{$\begin{array}{l}\text { Multnomah County (Ore.) Sanctions, Treatment, Opportunity, } \\
\text { and Progress (STOP) Drug Diversion Program }\end{array}$} \\
\hline (Finigan, 1998) & Yes & & \\
\hline (Goldkamp, White, and Robinson, 2001) & & & Yes \\
\hline $\begin{array}{l}\text { New Castle County (Del.) Drug Court } \\
\text { (Marlowe and others, 2004; Festinger and others, 2002) }\end{array}$ & & Yes & Yes \\
\hline $\begin{array}{l}\text { North Carolina Drug Treatment Court } \\
\text { (Craddock, 2002) }\end{array}$ & Yes & & \\
\hline $\begin{array}{l}\text { Okaloosa County (Fla.) Drug Court } \\
\text { (Peters and Murrin, 2000) }\end{array}$ & & & Yes \\
\hline $\begin{array}{l}\text { Orange County (Calif.) Drug Court Program } \\
\text { (Deschenes and others, 2001) }\end{array}$ & Yes & & Yes \\
\hline $\begin{array}{l}\text { Queens (N.Y.) Treatment Court } \\
\text { (Rempel and others, 2003) }\end{array}$ & Yes & & Yes \\
\hline $\begin{array}{l}\text { Rochester (N.Y.) Drug Treatment Court } \\
\text { (Rempel and others, 2003) }\end{array}$ & Yes & & \\
\hline $\begin{array}{l}\text { So. San Mateo County (Calif.) Drug Court } \\
\text { (Wolfe, Guydish, and Termondt, 2002) }\end{array}$ & Yes & & \\
\hline $\begin{array}{l}\text { St. Mary Parish (La.) Drug Court } \\
\text { (Anspach and Ferguson, 2003) }\end{array}$ & & & Yes \\
\hline $\begin{array}{l}\text { Suffolk County (N.Y.) Drug Treatment Court } \\
\text { (Rempel and others, 2003) }\end{array}$ & Yes & & Yes \\
\hline $\begin{array}{l}\text { Syracuse (N.Y.) Community Treatment Court } \\
\text { (Rempel and others, 2003) }\end{array}$ & Yes & & Yes \\
\hline $\begin{array}{l}\text { Washington State Drug Court Program } \\
\text { (Barnoski and Aos, 2003) }\end{array}$ & Yes & & \\
\hline
\end{tabular}


${ }^{b}$ Recidivism results for the Hamilton County evaluation were not included in our review because upon our further review, we found that the nonequivalent control group design did not sufficiently control for group differences that could have explained the reported (favorable) recidivism differences.

${ }^{\circ}$ The evaluation of the Kentucky Drug Court Program included three programs: (1) Fayette Drug Court program, (2) Jefferson County Drug Court program, and (3) Warren Drug Court program. The data for these three programs were combined in the analyses conducted. However, information about the program components and participants was reported separately for each program.

${ }^{d}$ We included the evaluation of the Las Cruces Municipal DWI Drug Court because it was an experiment that assessed recidivism. However, we did not include its results in our final review of recidivism outcomes because it is a specialty court that handles only misdemeanor driving while intoxicated (DWI) defendants.

${ }^{\mathrm{e}}$ The evaluation of Washington State Drug Court Program included six programs: those in (1) King, (2) Kitsap, (3) Pierce, (4) Skagit, (5) Spokane, and (6) Thurston counties. Limited information about the program components and participants were reported for each of the six programs. However, some of the recidivism analyses combined data from multiple counties.

To obtain information on our outcomes of interest-that is, recidivism, substance use relapse, and program completion-we used a data collection instrument to systematically collect information about the methodological characteristics of the evaluations, the participants and components of the drug court programs, and the outcomes of the participants and other comparable groups.

To assess the methodological strength of the 27 evaluations, we used generally accepted social science principles. ${ }^{6}$ For example, we assessed elements such as whether data were collected during or after program completion and the appropriateness of outcome measures, statistical analyses, and any reported results. Each evaluation was read and coded by a senior social scientist with training and experience in evaluation research methods. A second senior social scientist and other members of our evaluation team then reviewed each completed data collection instrument to verify the accuracy of the information included. Part of our assessment also focused on the quality of the data used in the evaluations as reported by the researchers and our observations of any problems with missing data, any limitations of data sources for the purposes for which

\footnotetext{
${ }^{6}$ Social science research standards are discussed in the scientific literature. For example, see Campbell, Donald T., and Julian Stanley, Experimental and Quasi-Experimental Designs for Research (Chicago: Rand McNally, 1963); Cook, Thomas D., and Donald T. Campbell, Quasi-experimentation: Design and Analysis Issues for Field Settings (Boston: Houghton Mifflin, 1990); and GAO, Designing Evaluations, GAO/PEMD-10.1.4 (Washington, D.C.: May 1991).
} 
To assess the cost-benefit analyses of drug court program evaluations, we reviewed all of the evaluations selected for our structured review that reported cost or benefit information. Of the 27 evaluations included in our in-depth review, 8 reported information about program costs and 4 about benefits. The 8 evaluations we included in our cost review are shown in table 2 .

Table 2: The Eight Drug Court Program Evaluations in Our Cost-Benefit Review

\begin{tabular}{lll}
\hline & \multicolumn{2}{c}{ Reported data on } \\
\cline { 2 - 3 } Drug court program evaluation & Benefits & Costs \\
\hline Included in cost-benefit analysis & Yes & Yes \\
\hline $\begin{array}{l}\text { Breaking the Cycle Program } \\
\text { (Harrell and others, 2003) }\end{array}$ & & Yes \\
\hline $\begin{array}{l}\text { D.C. Superior Court Drug Intervention Program } \\
\text { Harrell, Cavanagh, and Roman, 1998) }\end{array}$ & & Yes \\
\hline $\begin{array}{l}\text { Multnomah County (Ore.) STOP Drug Diversion } \\
\text { Program (Carey and Finigan, 2003) }\end{array}$ & Yes \\
\hline $\begin{array}{l}\text { Washington State Drug Court Program } \\
\text { (Barnoski and Aos, 2003) }\end{array}$ & Yes \\
\hline $\begin{array}{l}\text { Not included in cost-benefit analysis } \\
\begin{array}{l}\text { Douglas County (Neb.) Drug Court } \\
\text { (Martin, Spohn, Piper, and Frenzel-Davis, 2001) }\end{array}\end{array}$ & Yes \\
\hline $\begin{array}{l}\text { Kentucky Drug Court Programs } \\
\text { (Logan, Hoyt, and Leukefeld, 2001) }\end{array}$ & No \\
\hline $\begin{array}{l}\text { Los Angeles County (Calif.) Drug Court Program } \\
\text { (Deschenes and others, 1999) }\end{array}$ & No \\
\hline $\begin{array}{l}\text { Maricopa County (Ariz.) First Time Drug Offender } \\
\text { Program (Deschenes and others, 1996) }\end{array}$ & No \\
\hline
\end{tabular}

Source: GAO analysis of drug court program evaluations.

Four of the 8 evaluations reported sufficient data on both benefits and costs, which allowed us to assess the reported net benefits of the drug court programs. Specifically, we were able to determine whether the reduction of recidivism - the benefit-would outweigh the additional costs of a program. We used standard cost-benefit criteria to screen and assess these evaluations that reported cost and benefit information. Additionally, we reviewed methodologies describing approaches for conducting cost analyses of drug court programs. 
We selected the evaluations in our review based on their methodological strength; therefore, our results cannot be generalized to all drug court programs or their evaluations. Although the findings of the evaluations we reviewed are not representative of the findings of all evaluations of drug court programs, the evaluations consist of those published evaluations we could identify that used the strongest designs to assess drug court program effectiveness.

Finally, we interviewed drug court program researchers and officials at the Department of Justice, the National Institute on Drug Abuse, and the Office of National Drug Control Policy. We conducted our work from October 2003 through February 2005 in accordance with generally accepted government auditing standards. 


\section{Appendix II: Evaluations Used Multiple Approaches to Assess Selection Bias}

Most of the evaluations included in our review used quasi-experimental comparison groups. ${ }^{1}$ The use of quasi-experimental comparison groups can result in comparisons between drug court participants and comparison group members that differ on key variables related to recidivism. Systematic difference between comparison groups and treatment groups, called selection bias, threatens the validity of evaluation findings. Though design and analysis strategies differed, each of the quasiexperimental evaluations in our review used some combination of design and statistical methods to address the issue of selection bias. Approaches to address selection bias in design generally included attempts to choose comparison groups that share key commonalities with treatment groups (usually including likelihood of eligibility to participate in a drug court were it available) and therefore were less likely to differ on observed and unobserved characteristics related to recidivism. The evaluations in our review also included attempts to minimize the effects of selection bias through the application of various statistical methods.

\section{Comparison Groups Can Introduce the Problem of Selection Bias}

The observed differences in recidivism that we discuss in this report could arise from measured and unmeasured sources of variation between drug court participants and comparison group members. If comparison group members differed systematically from drug court participants on variables or factors that are also associated with recidivism and these variables were not accounted for by the design or analysis used in the evaluation, then the observed differences in recidivism could be due to these sources of variation rather than participation in the drug court program. For example, if successful drug court participants differed systematically in their substance abuse addiction problems from the members of the group against which they are compared, and if the differences in substance abuse addiction are not explicitly assessed in the evaluation, these differences, and not necessarily participation in the drug court program, could explain any observed recidivism differences. Similarly, if participants differed from comparison group members in their motivation to complete the drug court, recidivism differences could arise from these. Evaluations generally do not have measures of variables, such as motivation, that can be explicitly included in the analysis of drug court outcomes.

\footnotetext{
${ }^{1}$ In contrast to experimental control groups, where participants are deliberately randomly assigned to either treatment or control groups for purposes of comparison, the comparison groups in quasi-experimental groups are constructed from relatively comparable existing groups not receiving treatment. Quasi-experimental methods are often used to assess effects in the natural setting, where a true experiment may not be feasible.
} 
One way to address issues of selection bias is in the design of the comparison groups. Generally, random assignment of eligible participants to treatment and control groups addresses selection bias by randomly distributing individual differences between the treatment and control group. Another way to address selection bias is statistically-by forming comparison groups that consist of individuals that are as similar as possible to drug court participants and by using statistical techniques to control for observed differences, including sophisticated two-step procedures that attempt to address differences in selection into the drug court program. For the recidivism outcomes we reported, the evaluations in our review used design and statistical methods to address selection bias.

Evaluations Addressed Selection Bias through Design

Evaluations in our review were either experiments or quasi-experiments. The experiments randomly assigned eligible defendants to a drug court program or a control group of defendants who received conventional case processing. ${ }^{2}$ The quasi-experiments used one of two types of comparison groups:

- historical comparison group - formed from individuals who received conventional case processing during a period of time shortly before the drug court program was implemented and

- contemporaneous comparison group-formed from defendants (1) who were eligible for drug court but received conventional case processing during the same time period as the drug court program participants, (2) who were from a district within a court's jurisdiction from which arrestees were not eligible to participate in the drug court program, or (3) who had similar charges and were matched on characteristics.

If implemented as designed, experiments can provide strong evidence for the effectiveness (or lack thereof) of a drug court intervention. A key presumption of random assignment is that any individual factor that could be associated with the outcome of interest (recidivism) is randomly distributed between the experimental and control groups. Hence, if none of these factors are correlated systematically with assignment into groups, then the threat of selection bias is reduced. Presuming that the randomization is complete and that the experiment was carried out

\footnotetext{
${ }^{2}$ We use conventional case processing in this report to refer to the general set of criminal justice procedures that comparison group members receive.
} 
without high levels of attrition of subjects from either group, the observed differences in recidivism between the two groups would likely arise from the intervention, rather than observed or unobserved individual factors.

Several of the evaluations used quasi-experimental designs in which the comparison group members were chosen from defendants who appeared before the court during a period of time shortly before the drug court program was introduced and, based on certain observable characteristics, were deemed to be eligible to participate in the drug court program. Theoretically, if there were no significant changes in processes that led to defendants appearing in a court during the pre- and drug court periods, and if their eligibility for drug court participation could be determined, a historical comparison group would consist of individuals that share characteristics with drug court defendants. Alternatively, if there were a significant difference in processing between the pre-drug court and drug court periods (for example, such as a shift in prosecution priorities toward particular types of offenses or a change in the nature of a community's drug problem), then the historical comparison group could consist of defendants that differed systematically from the drug court participant group.

The historical comparison group in the evaluations we reviewed generally consisted of defendants who were arrested and arraigned in the court that offered the drug court program in a period immediately prior to the implementation of the drug court. In one case, the comparison group members were chosen from defendants on probation in the period prior to the drug court. To minimize possible bias that could arise from changes in court practices or the composition of defendants entering a court in the period prior to the implementation of a drug court, in the evaluations we reviewed, the prior periods generally ended within 4 months to 1 year before the implementation of the drug court program.

Another subset of the evaluations we included in our review used quasiexperiments with contemporaneous comparison groups. One comparison group consisted of defendants who met the drug court program's eligibility requirements but who were arrested in areas within a court's jurisdiction that did not enroll individuals in the drug court. Another comparison group was formed by selecting members from other, comparable jurisdictions. A third consisted of individuals who, while otherwise eligible to enroll in the drug court, were unable to participate because of logistical reasons. Others consisted of defendants charged with similar offenses as drug court participants and who were then matched on key variables. 
Evaluations Used a Variety of Statistical Methods to Minimize the Possible Effects of Selection Bias
All of the quasi-experiments that we reviewed, whether they used historical or contemporaneous comparison groups, used various statistical methods to control for individual differences between drug court participants and comparison group members on observable variables. Several evaluations used sophisticated statistical methods that not only adjusted results for individual level differences but also attempted to correct for selection bias by modeling unobserved differences between drug court and comparison group members. ${ }^{3}$ These methods reduce but do not completely eliminate potential bias from unobserved confounding factors. The extent to which they reduce bias depends upon the richness and quality of the control variables that are used to estimate the models.

These methods essentially use statistical models to predict individual probabilities of participation in the drug court program (regardless of actual participation). The models predict the probability, sometimes called a propensity score, based on variation in individual level characteristics (for example, criminal histories and demographic attributes) that offenders in a given group would participate. Some of the evaluations that we reviewed incorporated this technique as the first stage of a two-stage model that estimated recidivism differences. Others used it to identify the individuals to include in a comparison group.

Other studies matched comparison group members to drug court participants on a more limited set of demographic and criminal justice variables (such as type of charge and prior criminal history) and then, post-matching, used various methods to control for differences on unmatched variables. A presumption behind these matching methods is that by selecting for inclusion in the comparison group only those defendants who matched drug court participants on these observed characteristics, the evaluation would create a comparison group that was similar in composition to the drug court participants. A limited set of matching variables that is based largely upon demographic variables may be unlikely to capture all of the individual-level sources of variation in recidivism that could account for differences between the drug court participants and comparison group members. Therefore, these evaluations attempted to control for differences in key, nonmatch variables (such as criminal justice risk-level differences) in their analysis.

${ }^{3}$ See, for example, Heckman, James, Hidehiko Ichimura, and Petra Todd (1997). "Matching as an Econometric Evaluation Estimator: Evidence from a Job Training Programme," Review of Economic Studies, Vol. 64, No. 4, pp. 605-654. 
Some of the evaluations attempted to control for individual-level differences between the drug court participants and the comparison group members using various linear and nonlinear (e.g., logistic) regression methods. This approach relies on the assumption that the observed characteristics included in the regression are the key variables that predict recidivism. The regression models adjust the results for differences between the two samples on these characteristics and allow the researcher to avoid making incorrect inferences about recidivism differences because one group (either treatment or comparison) differs systematically from the other in the presence of the key variables that are associated with recidivism. Evaluations that used regression methods generally made efforts to control for variables that are known to be related to recidivism, such as criminal history, type and number of charges, and age. Table 3 describes the comparison groups used in the evaluations we reviewed and the methods used by these evaluations to address selection bias. 
Table 3: Research Designs, Comparison Groups, and Methods to Address Selection Bias for Evaluations GAO Used in Recidivism Analysis

\begin{tabular}{ll}
\hline Drug court program and design & Comparison group used in evaluation \\
\hline Experimental design &
\end{tabular}

Baltimore City Drug Treatment Court Randomly assigned from the initial pool of willing, eligible defendants to a control group that received "treatment as usual," which included less intensive drug testing, probation, judicial monitoring, and treatment.

D.C. Superior Court Drug

Intervention Program

Randomly assigned from the initial pool of eligible drug court participants to a standard (control) docket. Participants received services such as supervision, drug tests (twice weekly), judicial monitoring, and were encouraged to seek community treatment.

Maricopa County First Time Drug Offender Program
All individuals identified as eligible for the drug court program were randomly assigned to one of three study groups at the time of their initial probation assignment. The three study groups were:

1. probation with no testing;

2. probation with low-rate (monthly) drug testing; and

3. probation with high-rate (biweekly) drug testing.
Methods to address selection bias

Random assignment to control prior to appearance before a drug court judge, who made final determinations for drug court entry.

Random assignment and various regression methods to control for individual differences between drug court participants and control group members, such as age, gender, prior criminal history, severity of drug use, and employment status.

Random assignment.
Regression methods that control for individual differences and a two-stage estimation procedure to account for unmeasured sample differences.
Historical arrestees: sample drawn from arrestees in a drug use forecasting project in the Birmingham jail over a 2-month period in the year prior to the start of the treatment court. Arrestees were chosen using the same criteria to select treatment court participants: age, county, felony charges, and involvement with illegal drugs.

Breaking the Cycle Program, Jacksonville

\section{Historical arrestees: sample drawn from} arrestees in the Duval County jail over a 4month period that ended 5 months prior to the start of the treatment court. Arrestees were chosen using the same criteria to select treatment court participants: age, county of residence (Duval), felony charges, and involvement with illegal drugs.
Regression methods that control for individual differences and a two-stage estimation procedure to account for unmeasured sample differences. 


\begin{tabular}{|c|c|c|}
\hline Drug court program and design & Comparison group used in evaluation & Methods to address selection bias \\
\hline $\begin{array}{l}\text { Breaking the Cycle Program, } \\
\text { Tacoma }\end{array}$ & $\begin{array}{l}\text { Historical arrestees: sample drawn from } \\
\text { arrestees in the Pierce County jail over a 4- } \\
\text { month period that ended } 5 \text { months prior to } \\
\text { the start of the treatment court. Arrestees } \\
\text { were chosen using the same criteria to select } \\
\text { treatment court participants: age, county of } \\
\text { residence (Pierce), felony charges, and } \\
\text { involvement with illegal drugs. }\end{array}$ & $\begin{array}{l}\text { Regression methods that control for individual } \\
\text { differences and a two-stage estimation } \\
\text { procedure to account for unmeasured sample } \\
\text { differences. }\end{array}$ \\
\hline Bronx Treatment Court & $\begin{array}{l}\text { Historical arrestees: defendants arrested in } \\
\text { the Bronx in the } 4 \text { months prior to the } \\
\text { opening of the drug court on selected felony } \\
\text { charges of criminal sale of a controlled } \\
\text { substance. }\end{array}$ & $\begin{array}{l}\text { Propensity score matching methodology (to } \\
\text { identify comparison group members having } \\
\text { similar predicted probabilities of participating in } \\
\text { the drug court as drug court participants); match } \\
\text { model based on age, race, specific charges, and } \\
\text { various criminal history measures. Comparison } \\
\text { group members matched to the drug court } \\
\text { participant having the nearest propensity score. }\end{array}$ \\
\hline
\end{tabular}

Chester County Drug Court Program Historical probationers: defendants placed on probation during the 10-month period prior to the inception of the drug court program who would have been eligible had the drug court program existed (i.e., charged with nonmandatory drug offenses, had no prior violent offenses, and were not on probation or parole).

Escambia County Drug Court

Jackson County Drug Court

Queens Treatment Court

Historical arrestees: defendants arrested and arraigned in Escambia County over a 27month period that ended in the month prior to the beginning of the drug court. Selected on the same type of charges as drug court participants.

Historical arrestees: defendants arrested in Jackson County over a 3-year period that ended in the 15 months prior to the beginning of the drug court. Selected on the same type of charges as drug court participants.

Historical arrestees: defendants arrested in Queens in the year prior to the opening of the drug court on a most serious charge of criminal sale or possession of drugs (that met charge eligibility for drug court). Excluded defendants who did not meet the drug court's paper eligibility criteria, i.e., current and prior violence and those cases in which the arrest did not lead to a conviction.

So. San Mateo County Drug Court
Historical arrestees: defendants arrested and processed before the start of the drug court but who would have been eligible for the drug court.
Comparison group was similar to the drug court sample in demographic characteristics (age, race, and gender), prior record, and prior drug treatment characteristics. Author and county officials were unaware of historical events that would have caused threats to validity of comparison.

Instrumental variable approach that controls for the probability of participation in the drug court program and models unobserved motivational differences between participants and nonparticipants.

Instrumental variable approach that controls for the probability of participation in the drug court program and models unobserved motivational differences between participants and nonparticipants.

Propensity score matching methodology (to identify comparison group members having similar predicted probabilities of participating in the drug court as drug court participants); match model based on age, race, specific charges, and various criminal history measures. Comparison group members matched to the drug court participant having the nearest propensity score.

Regression methods to control for individual differences on key variables, such as ethnicity, prior convictions, primary language, and severity of charges. 


\begin{tabular}{lll}
\hline \hline Drug court program and design & Comparison group used in evaluation & Methods to address selection bias \\
\hline Suffolk County Drug Treatment & Historical arrestees: defendants arrested in & Propensity score matching methodology (to \\
Court & Suffolk County in the year prior to the & identify comparison group members having \\
& opening of the drug court on a most serious & similar predicted probabilities of participating in \\
& charge of felony or misdemeanor criminal & the drug court as drug court participants); match \\
& possession of a controlled substance (that & model based on age, race, specific charges, and \\
& met eligibility for drug court). Excluded & various criminal history measures. Comparison \\
& defendants with current violent charges or & group members matched to the drug court \\
& prior violent convictions and those cases in & participant having the nearest propensity score.
\end{tabular}

Syracuse Community Treatment
Court
which the arrest did not lead to a conviction.

Syracuse Community Treatment
Historical arrestees: defendants arrested in Syracuse City in the year prior to the opening of the drug court on a most serious charge of felony or misdemeanor criminal possession of a controlled substance (that met drug court charge eligibility). Excluded defendants with prior violent convictions or pending violent charges and those cases in which the arrest did not lead to a conviction.
Propensity score matching methodology (to identify comparison group members having similar predicted probabilities of participating in the drug court as drug court participants); match model based on age, race, specific charges, and various criminal history measures. Comparison group members matched to the drug court participant having the nearest propensity score.

\section{Quasi-experimental, con

Brooklyn Treatment Court

\section{Contemporaneous: drug felony defendants} arrested in Brooklyn but not screened in the drug court, primarily because they were arrested within one of the two geographic zones that were ineligible to send defendants to the drug court. Defendants met the same paper eligibility criteria as drug court participants. Excluded defendants with prior violent felony or misdemeanor convictions, with current violent offense charges, and those cases in which the arrest did not lead to a conviction.

Clark County Drug Court Contemporaneous arrestees: sample drawn from criminal defendants who had charges filed in the Clark County District Courts but did not enter the drug court. Sample stratified on drug type and type of charge.

Douglas County Drug Court

Douglas County Drug Court

Kentucky Drug Court Programs
Contemporaneous: felony drug arrestees who had charges filed in court and traditionally adjudicated. ${ }^{a}$ Most had no more than one prior felony conviction, and few had been convicted of a prior violent felony. Slightly less than half were characterized as medium- or high-risk offenders.

Contemporaneous: assessed offenders,
combined felony and misdemeanor charge or conviction.
Propensity score matching methodology (to identify comparison group members having similar predicted probabilities of participating in the drug court as drug court participants); match model based on age, race, specific charges, and various criminal history measures. Comparison group members matched to the drug court participant having the nearest propensity score.

Regression methods to control for individual differences in gender, race/ethnicity, age, prior convictions, number of charges and types of charges (e.g., drug possession or sales and economic crimes), prior controlled substances types, and recidivism in the year after sentencing.

Matched to drug court participants on most serious offense, gender, race and ethnicity, and age. Risk-level data were not available for this group. Regression methods to control for prior criminal history.

Regression methods to control for individual differences in age, gender, race, location of court, year of participation, and criminal justice involvement. 


\section{Drug court program and design \\ Los Angeles County Drug Court}

Program

\section{Comparison group used in evaluation \\ Contemporaneous: felony offenders charged with drug possession but sentenced at trial to probation. Drawn from the same pool of offenders screened for participation in the drug court.}

\section{Methods to address selection bias}

Matched with the sample of drug court

defendants of a risk scale score (a composite scale based on criminal justice and social factors and used to determine release risk), time of hearing, gender, and age. Separate analyses done between drug court and both comparison group members having various levels of risk.

\section{Multnomah County STOP Drug Diversion Program}

North Carolina Drug Treatment
Court

\begin{tabular}{ll}
\hline Orange County Drug Court Program & $\begin{array}{l}\text { Contemporaneous defendants who had } \\
\text { similar charges as the drug court participants } \\
\text { and were sentenced to probation. Drawn } \\
\text { from the same pool of offenders screened for } \\
\text { participation in the drug court. }\end{array}$
\end{tabular}

Rochester Drug Treatment Court
Contemporaneous arrestees who were eligible for the STOP program but did not receive it. Arrested for possession of controlled substance and considered to be eligible for STOP but did not receive it.

Contemporaneous probationers who would have been eligible for the drug court but were not admitted. Comparison group was screened for chemical dependence and sample selected based on drug addiction (from screening) and eligibility for drug court. Contemporar

Matched sample approach to select a group of eligible clients who were representative of program participants on age, gender, race/ ethnicity, and prior criminal history.

Regression methods to control for individual differences in age, gender, ethnicity, type of offense (for example, property or drug), offense seriousness, and graduation status.

Matched to drug court participants on gender, race and ethnicity, and age.

Contemporaneous arrestees: defendants Propensity score matching methodology (to arrested in Rochester during the same period identify comparison group members having of time as the drug court was in operation but similar predicted probabilities of participating in who were not arraigned before judges supportive of the drug court program. Excluded defendants that did not meet the drug court's paper eligibility criteria (i.e., current and prior violence) and those cases in which the arrest did not lead to a conviction. the drug court as drug court participants); match model based on age, race, specific charges, and various criminal history measures. Comparison group members matched to the drug court participant having the nearest propensity score.

\section{and contemporaneous comparison groups}

\begin{tabular}{ll}
\hline Quasi-experimental, both historical and contemporaneous comparison group \\
\hline Washington State Court Program & Historical and contemporaneous defendants: \\
& Historical group: defendants with cases filed \\
in the 2 years prior to the start of the drug & court in each of the county drug court \\
programs included in the evaluation. & Contemporaneous group: defendants with \\
similar cases who were processed in \\
counties without drug courts that were \\
comparable to the counties that did have \\
drug courts.
\end{tabular}

Source: GAO analysis of drug court program evaluations.

${ }^{a}$ While these defendants consisted primarily of those arrested during the time the drug court program was in operation (a contemporaneous comparison), some individuals who were arrested in the 3 months prior to the start of the drug court program were included.

Various statistical methods including regressions to control for individual differences in age, gender, ethnicity, prior youth and adult convictions, current charges; propensity score matching to identify comparison group members with similar predicted probabilities of entering the drug court. 


\section{Appendix III: GAO Criteria for Assessing Evaluations of Drug Court Programs' Cost- Benefit Analyses}

In this appendix, we outline the criteria we used in assessing the costbenefit analyses of drug court program evaluations, and we discuss how the evaluations we reviewed followed these criteria in their analyses.

The Evaluations We Reviewed and the Net Benefit Measure
Cost-benefit analysis determines the costs associated with implementing or operating a program and weighs that cost against any benefits expected from the program. The results of a cost-benefit analysis can be represented as either a net benefit—calculated as total benefits minus total costs-or a benefit-to-cost ratio-calculated as total benefits divided by total costs.

We used the net benefit-benefit minus cost—measure to represent the cost-benefit analyses of the drug court programs we reviewed. Net benefit can be used to evaluate the cost savings - that is, the benefits-for each participant in a drug court program relative to the cost savings for each offender processed by conventional case processing in the same jurisdiction.

To assess the cost-benefit analyses of drug court program evaluations, we reviewed all of the evaluations selected for our structured review that reported cost or benefit information. Of the 27 evaluations included in the structured review, 8 reported information about program costs and 4 about benefits. The 8 evaluations we included in our cost-benefit review are shown in table 4. 
Table 4: The Eight Drug Court Program Evaluations in Our Cost-Benefit Review

\begin{tabular}{lll}
\hline & \multicolumn{2}{c}{ Reported data on } \\
\cline { 2 - 3 } Drug court program evaluation & Benefits & Costs \\
\hline Included in cost-benefit analysis & Yes & Yes \\
\hline $\begin{array}{l}\text { Breaking the Cycle Program } \\
\text { (Harrell and others, 2003) }\end{array}$ & & Yes \\
\hline $\begin{array}{l}\text { D.C. Superior Court Drug Intervention Program } \\
\text { (Harrell, Cavanagh, and Roman, 1998) }\end{array}$ & & Yes \\
\hline $\begin{array}{l}\text { Multnomah County (Ore.) STOP Drug Diversion } \\
\text { Program (Carey and Finigan, 2003) }\end{array}$ & Yes & Yes \\
\hline $\begin{array}{l}\text { Washington State Drug Court Program } \\
\text { (Barnoski and Aos, 2003) }\end{array}$ & Yes \\
\hline $\begin{array}{l}\text { Not included in cost-benefit analysis } \\
\text { (Martin, Spohn, Piper, and Frenzel-Davis, 2001) }\end{array}$ & & Yes \\
\hline $\begin{array}{l}\text { Kentucky Drug Court Programs } \\
\text { (Logan, Hoyt, and Leukefeld, 2001) }\end{array}$ & No & Yes \\
\hline $\begin{array}{l}\text { Los Angeles County (Calif.) Drug Court Program } \\
\text { (Deschenes and others, 1999) }\end{array}$ & No & Yes \\
\hline $\begin{array}{l}\text { Maricopa County First Time Drug Offender } \\
\text { Program (Deschenes and others, 1996) }\end{array}$ & No \\
\hline
\end{tabular}

Source: GAO analysis of drug court program evaluations.

Four of the 8 evaluations reported sufficient data on both costs and benefits, which allowed us to assess the reported net benefits of the drug court programs. Specifically, we were able to determine whether the reduction of recidivism - the benefit—would outweigh the additional costs of a program. 


\section{Appendix III: GAO Criteria for Assessing \\ Evaluations of Drug Court Programs' Cost- \\ Benefit Analyses}

\section{Criteria for Assessing a Drug Court Program's Cost- Benefit Analysis}

Conducting a cost-benefit analysis is theoretically straightforwarddetermine the monetary value of a program's benefits and compare that value with the monetary value of the program's costs. However, the analysis is more complicated in practice because of decisions that have to be made about who to include as recipients of the benefits and how to measure costs and benefits. ${ }^{1}$ On the basis of the general principles of costbenefit analysis, we identified five criteria that we used in assessing the cost-benefit analyses of the drug court programs we reviewed. Table 5 describes these criteria; where further explanation is needed, we discuss them in the text that follows.

Table 5: Five Criteria for Assessing a Cost-Benefit Analysis of a Drug Court Program

\begin{tabular}{ll}
\hline Criterion & Description \\
\hline 1. States the program's purpose & $\begin{array}{l}\text { In general, the purpose of a drug court program is to reduce repeated criminal behavior-to } \\
\text { reduce recidivism—by reducing offenders' substance-using behavior. }\end{array}$ \\
\hline 2. Identifies the baseline & $\begin{array}{l}\text { The baseline, or alternative, is what would happen to an offender if the drug court program } \\
\text { did not exist. }\end{array}$ \\
\hline 3. Assesses all relevant costs & $\begin{array}{l}\text { The costs involved in a drug court program are those associated with the program's } \\
\text { operation and those associated with the baseline. }\end{array}$ \\
\hline 4. Assesses all relevant benefits & $\begin{array}{l}\text { Benefits usually attributed to drug court programs are costs avoided because of reduced } \\
\text { recidivism; they accrue to the criminal justice system and potential victims of crime. Other } \\
\text { benefits an analysis could consider include reduced medical costs and successful program } \\
\text { participants' increased productivity. }\end{array}$ \\
\hline $\begin{array}{l}\text { 5. Assesses uncertainty in cost and } \\
\text { benefit estimates }\end{array}$ & $\begin{array}{l}\text { Most cost and benefit estimates entail uncertainty from imprecision in the data underlying } \\
\text { the analysis and the assumptions built into the analysis. Assessing uncertainty enhances } \\
\text { confidence in the estimates used in evaluation. }\end{array}$ \\
\hline
\end{tabular}

Source: GAO analysis.

A cost-benefit analysis should identify what the baseline program is. In the case of drug court programs, the analysis should state what would happen to an offender if the drug court program did not exist. The costs and benefits of this alternative program or case processing, called the baseline, are the standard by which the drug court program costs and benefits are judged. There is no single baseline against which all drug court programs are compared. For example, one jurisdiction may offer drug court program

\footnotetext{
${ }^{1}$ Generally, a cost is the value of resources used to achieve a benefit. Economic costs consider the opportunity cost, which is the value of the resources in their best alternative use. The costs to and the benefits that accrue to all members of society, rather than just to its taxpaying members, should be included in the analysis. For example, benefits from a decrease in crime, such as reduced victimization, accrue to all members of society, regardless of whether they are taxpayers, and should be included.
} 
participation to defendants as an alternative for jail, another as an alternative for probation.

\section{Assesses All Relevant Costs}

\section{Determining Relevant Costs}

Measuring Drug Court Program and Baseline Program Costs
A cost-benefit analysis should enumerate and assess all relevant costs. A cost-benefit analysis of a drug court program should consider two sets of costs - those associated with the program's operation and those associated with the baseline. For both sets of costs, the analysis should determine which costs are relevant and then measure them.

Drug court programs often require additional expenses from criminal justice system agencies, although these may differ from program to program. The true cost of a drug court program consists of these expenses - the resources that would have been used in their next best alternative use-if not used for the program. Drug court programs have several basic elements, one of which is ongoing monitoring of the participants by a judge or other personnel in the criminal justice system. ${ }^{2}$ Others are regular status hearings and drug testing, substance abuse treatment, and the prescription of sanctions for noncompliance with program requirements. While an analysis should consider all of these costs, it should not consider costs that were incurred before the program began (that is, sunk costs) since they are not relevant to the current decision to fund or continue funding the program.

In addition to the program's costs, the analysis should include the costs of the baseline. These depend on the types of offenders who are eligible for the drug court program in each jurisdiction and the alternative program or processing available for them. The baseline costs may include the cost of traditional adjudication (including a judge's time during the early phases of judicial processing), the costs of jail time served, or costs of probation (such as the salaries of probation officers or any required monitoring).

The various methods of measuring or estimating costs require varying amounts of time, data, and analysis. The most straightforward way of

\footnotetext{
${ }^{2}$ In an assessment of the costs associated with the salaries of criminal justice personnel, costs that are directly attributable to the drug court program (such as the salary of a fulltime drug court judge) should be included. Costs that are incurred jointly by the program and other activities (such as costs for probation officers with shared caseloads) should be allocated among the program and the activities, according to some generally accepted accounting principles or standards. Finally, costs that would be incurred in the absence of the program (such as costs for nondedicated police personnel) should be excluded from the analysis.
} 

use budget or expenditure figures from the agencies involved to calculate average costs. ${ }^{3}$ While this method has the advantage of simplicity, average cost may be a misleading measure of resource costs if it does not accurately portray the resources defendants actually used.

For example, a few very high cost program participants could skew the average cost to such an extent that actual cost appears to be larger than it is. This is especially important in assessing average costs associated with the baseline program. The average baseline defendant in a jurisdiction may be very different from participants in a drug court program. Therefore, comparing costs associated with the average defendant with those of the average drug court participant may not be valid.

A less simple approach, requiring a more intensive use of time and data, is to conceptualize the cost of drug court program participation as a series of transactions within the criminal justice system agencies. ${ }^{4}$ Since a defendant interacts with a number of these agencies, this method requires obtaining data about each defendant from each agency. These data can be aggregated for individual defendants to determine the total amount of resources used per participant, and these resources can then be multiplied by their price. This approach has the advantage of allowing a better determination of the true cost of drug court participation, relative to participation in an alternative program. However, since it is more labor intensive, jurisdictions may not have records organized in a way that allows for tracking individuals across agencies.

Assesses and Measures All Relevant Benefits
As with costs, all relevant benefits of the drug court program should be assessed relative to the baseline. ${ }^{5}$ The typical benefit attributed to drug

\footnotetext{
${ }^{3}$ Average costs are calculated by dividing the budget totals by the number of drug court program cases in a given year and by the number of baseline, or nondrug, cases in the same year.

${ }^{4}$ This is called the transaction cost approach. For more information about this methodology, see Carey, S. M., and M. W. Finigan, A Detailed Cost Analysis in a Mature Drug Court Setting: A Cost-Benefit Evaluation of the Multnomah County Drug Court, (Portland, Ore.: NPC Research, July 2003).

${ }^{5}$ The present value of estimated costs and benefits should be calculated. Researchers should identify the follow-up period in which the benefits would accrue. The value of future benefits should be discounted by an appropriate interest rate, to account for the fact that these benefits are deferred.
} 

benefits that could be considered in the analysis include reduced medical costs and increased worker productivity stemming from reduced drug dependency.

Reductions in recidivism can lead to benefits, or cost savings, for criminal justice agencies and for potential victims of crime. A reduction in the number of arrests would result in a reduction in expenditures for the agencies, including police, prosecutors, courts, corrections departments, and probation agencies.

Potential victims benefit from reduced recidivism. Benefits accrued because of reduced victimization include direct monetary costs, such as the value of stolen property and medical expenses, and quality-of-life costs related to pain and suffering. Not including pain and suffering costs would underestimate the true cost of crime, but some researchers exclude these intangibles because it is difficult to assign appropriate dollar values to them. This results in a more conservative estimate of the benefit of the drug court program.

In addition, the analysis should, to the extent possible, assess benefits to society from a reduction in substance abuse. These benefits may include avoided medical care costs, such as medical services a treated drug addict did not require. Additionally, if drug court programs are effective, the labor market outcomes of the participants may improve. For example, successful participants may be unemployed less often or may earn higher wages because of increased productivity. To the extent that they may therefore pay higher taxes, such taxes are benefits to taxpayers in general. ${ }^{6}$

Challenges in Measuring Drug Court Program Benefits
The simplest approach to measuring the benefits of reduced recidivism is using arrest data. This approach has the appeal that an arrest is usually the beginning of expenditures by a criminal justice agency. Then, the value of this benefit per arrest can be estimated in the same way that costs are estimated-by using agency budgets to calculate the average savings from each avoided arrest.

${ }^{6}$ These benefits may be difficult to quantify, but earnings and employment data could be estimated through surveys of participants or could be obtained from state unemployment insurance agencies. 

well. However, this approach requires the assumption that each criminal act results in an arrest. To the extent that this is not true, the estimation of victimization may be underestimated by a significant margin. Another approach to measuring victimization would be to use self-reported criminal behavior by the drug court program and comparison group participants. However, this approach relies on the forthrightness of the defendants, which is not ideal. Since both of these methods have drawbacks, any measurement of criminal victimization is much more uncertain than measures of expenditures by the agencies.

Measuring the cost of crime may also be problematic. Estimates of the costs of crimes at the national level are available in the literature. ${ }^{7}$ For example, these can provide an estimate of the cost of a burglary, and a researcher can apply the cost to the number of burglaries by the participant. Ideally, an analysis would also include the costs of crimes specific to the drug court program's jurisdiction to account for regional differences. For example, the average value of a car stolen in Miami might be different from the average value of a car stolen in Tallahassee.

\section{Assesses Uncertainty in Cost and Benefit Estimates}

The uncertainty in most cost and benefit estimates is the result of imprecision in the underlying data used in the analysis and the assumptions on which the analysis is built. Assessing uncertainty can enhance the confidence in the estimates in the evaluation. Useful information for an analysis to report includes the estimates of costs and benefits and the sensitivity of the cost and benefit estimates to assumptions made in the analysis.

Estimates of costs and benefits should take into account how likely it is that a particular outcome (for example, arrest for a crime that will warrant participation in the drug court program) will occur, in addition to the value (for example, the cost to victims, the criminal justice expenditures) of that outcome. Taking account of the likelihood of occurrence allows the researcher to provide a better assessment of how reliable the data-the costs and benefits-are.

\footnotetext{
${ }^{7}$ A commonly cited reference is Miller, T. R., M. A. Cohen, and B. Wiersema, Victim Costs and Consequences: A New Look (Washington, D.C.: National Institute of Justice, Office of Justice Programs, Department of Justice, January 1996).
} 

assessment of an analysis, it is helpful to know which assumptions can be changed without altering the conclusion of the analysis. Sensitivity analysis, or systematically varying the assumptions to see what effect variations have on estimated outcomes, can be applied to several components of a drug court program's cost analysis. ${ }^{8}$ For example, one assumption in the criminal justice area is the numerical relationship between the commission of a crime and the arrest rate. Not every crime results in an arrest, but a cost-benefit analysis may have been able to examine only arrest data, given the lack of other data available. Using arrest data assumes, in effect, that every crime does result in an arrest-an assumption that is likely to underestimate the change in crime that the public experiences. A sensitivity analysis could examine this possible understatement by increasing the study's assumed rate of crime per arrest (for example, the Washington State study assumes that 20 percent of robberies result in an arrest) to better approximate the actual crime rate.

\section{How the Drug Court Evaluations We Reviewed Used the Identified Cost- Benefit Principles}

We reviewed eight evaluations of 10 drug court programs for their use of the criteria. At least five of these evaluations made a concerted effort to assess all relevant costs as well as benefits. Only two evaluations assessed uncertainty. However, the two evaluations that conducted sensitivity analyses were two of the three that did not present costs and benefits separately so as to allow for an assessment of net benefits. Table 6 summarizes the evaluations we reviewed and their application of the five criteria in their assessments.

\footnotetext{
${ }^{8}$ A sensitivity analysis does not, however, provide information about the range and distribution of the possible values of a given outcome. Additional analysis can allow a researcher to determine the likely range of an estimated outcome. In essence, additional analysis can provide an upper and a lower bound of an estimate, giving an indication of how much uncertainty there is in the outcome. For example, researchers may estimate how much time a judge spends on a drug court program participant's case, and the estimate may be high or low. The range of possible values of time spent by a judge can be defined, which can help in assessing how reliable the costs associated with a judge's time are in an analysis.
} 
Table 6: Summary of Criteria Applied in Eight Drug Court Program Evaluation Assessments

\begin{tabular}{|c|c|c|c|c|c|c|c|}
\hline \multirow{2}{*}{$\begin{array}{l}\text { Drug court program } \\
\text { evaluation }\end{array}$} & \multirow{2}{*}{$\begin{array}{l}\text { Stated } \\
\text { purpose }\end{array}$} & \multirow{2}{*}{$\begin{array}{l}\text { Identified } \\
\text { baseline }\end{array}$} & \multicolumn{2}{|c|}{ Assessed costs } & \multicolumn{2}{|c|}{ Assessed benefits } & \multirow[b]{2}{*}{$\begin{array}{l}\text { Assessed } \\
\text { uncertainty }\end{array}$} \\
\hline & & & Drug court & Baseline & Recidivism & Other & \\
\hline \multicolumn{8}{|l|}{$\begin{array}{l}\text { BTC Program (Harrell } \\
\text { and others, 2003) }\end{array}$} \\
\hline Birmingham, Ala. & Yes & Yes & Yes & Yes & Yes & No & No \\
\hline Jacksonville, Fla. & Yes & Yes & Yes & Yes & Yes & No & No \\
\hline Tacoma, Wash. & Yes & Yes & Yes & Yes & Yes & No & No \\
\hline $\begin{array}{l}\text { D.C. Superior Court } \\
\text { Drug Intervention } \\
\text { Program (Harrell, } \\
\text { Cavanagh, and Roman, } \\
\text { 1998) }\end{array}$ & Yes & Yes & Yes & Yes & Yes & No & No \\
\hline $\begin{array}{l}\text { Douglas County (Neb.) } \\
\text { Drug Court (Martin, } \\
\text { Spohn, Piper, and } \\
\text { Frenzel-Davis, 2001) }\end{array}$ & Yes & Yes & Yes & Yes & No & No & No \\
\hline $\begin{array}{l}\text { Kentucky Drug Court } \\
\text { Programs (Logan, Hoyt, } \\
\text { and Leukefeld, 2001) }\end{array}$ & Yes & No & Yes & No & $\mathrm{No}^{\mathrm{a}}$ & No & Yes \\
\hline $\begin{array}{l}\text { Los Angeles County } \\
\text { (Calif.) Drug Court } \\
\text { Program (Deschenes } \\
\text { and others, 1999) }\end{array}$ & Yes & No & Yes & Yes & No & No & Yes \\
\hline $\begin{array}{l}\text { Maricopa County First } \\
\text { Time Drug Offender } \\
\text { Program (Deschenes } \\
\text { and others, 1996) }\end{array}$ & Yes & Yes & Yes & Yes & No & No & No \\
\hline $\begin{array}{l}\text { Multnomah County } \\
\text { (Ore.) STOP Drug } \\
\text { Diversion Program } \\
\text { (Carey and Finigan, } \\
\text { 2003) }\end{array}$ & Yes & Yes & Yes & Yes & Yes & No & No \\
\hline $\begin{array}{l}\text { Washington State Drug } \\
\text { Court Program } \\
\text { (Barnoski and Aos, } \\
\text { 2003) }\end{array}$ & Yes & Yes & Yes & Yes & Yes & No & No \\
\hline
\end{tabular}

Source: GAO analysis of drug court program evaluations.

${ }^{a}$ The Kentucky study does include estimates of benefits from reduced recidivism, but does not appear to include victimization costs. 


\section{All Evaluations Stated the Program's Purpose}

All eight evaluations provided a statement of the purpose of the drug court program, although the purpose of the programs varied somewhat one from another. Evaluations of some of the programs-for example, those in Kentucky, Washington, D.C., and Multnomah County-explicitly stated that the purpose was to address the source of criminal behavior-drug addiction, dependency, and the like-in order to reduce recidivism. None of the evaluations, however, included reduced drug dependency in their calculation of net benefits.

\section{All Evaluations Identified a Baseline}

Of the eight evaluations we reviewed, five compared drug court program participants with the baseline of conventional case processing in the criminal courts in their jurisdictions. The evaluation of the D.C. Superior Court Drug Intervention Program used a different baseline for comparison. This program was an experiment that randomly assigned drug felony defendants to one of three court dockets. The standard docket offered defendants weekly drug testing, judicial monitoring, and encouragement to seek treatment in the community. The sanctions docket offered a program of graduated sanctions with weekly drug testing, judicial monitoring of drug use, and referral to community-based treatment. The treatment docket offered weekly drug testing and an intensive daily treatment program based in D.C. Superior Court. The evaluation studied the sanctions and treatment docket participants against the outcomes of the standard docket participants.
The Evaluations Varied in Assessing Costs
The eight evaluations varied in the types of costs reported. All eight included only costs directly attributable to drug court programs. None attempted to allocate any shared costs incurred jointly by a drug court program and another activity not directly related to the program (such as policing). Further, no evaluation included sunk costs. All eight evaluations included direct program costs such as urine analysis. However, they varied in reporting costs for adjudication and sanctions. Six of the eight evaluations included costs of adjudication or sanctions. ${ }^{9}$

\footnotetext{
${ }^{9}$ Breaking the Cycle, D.C. Superior Court, Multnomah County, and Washington State evaluations considered adjudication and sanctions cost. Douglas County did not include sanctions costs, while Maricopa County did include confinement and supervision costs. The Los Angeles and Kentucky drug court program evaluations did not include adjudication or sanction costs.
} 
Including Baseline Costs

Estimating Costs
All of the evaluations, except for the Kentucky state evaluation, attempted to include the cost of the baseline in the analysis. Consequently, this evaluation did not report a net benefit value.

The evaluations varied in how they estimated costs. The most common method was to compute average costs. The Multnomah County evaluation differed in that it determined the cost to the agencies directly from the administrative records on the drug court program participants and the comparison group. In addition, the researchers on this evaluation followed a smaller sample of drug court program and control group participants through the system, tracking the use of resources in the various transactions associated with them. For example, the researchers used a stopwatch at arraignments to determine how much time the judge and other drug court staff spent in this process.
The Evaluations Varied in Assessing Benefits
In their estimation of benefits attributable to the drug court programs, five of the evaluations included estimates of drug court program and criminal justice system costs and avoided victimization costs (Breaking the Cycle, the D.C. Superior Court Drug Intervention Program dockets, Kentucky, Multnomah County, and Washington State). The D.C. Superior Court and Breaking the Cycle evaluations differed substantially from the others in both the method of measuring victimization and the victim costs. Rather than using arrest as the indicator of crimes committed, the evaluations used self-reported criminal activity. In addition, the studies did not use "quality of life" costs in their measure of cost of crime.

One evaluation estimated just drug court program costs avoided (Douglas County, Nebraska). One evaluation (Los Angeles County) included only criminal justice system costs avoided during the treatment period, but it did not cover recidivism. The Maricopa County evaluation only reported average costs.

\section{The Evaluations' Assessment of Uncertainty Was Limited or Nonexistent}

No evaluation we reviewed presented the likelihood of estimated costs and benefits, and only two evaluations conducted sensitivity analysis. In the Los Angeles County Drug Court evaluation, participants were partitioned into low-risk, medium-risk, and high-risk groups, on the basis of criminal history and other risk factors. The Kentucky Drug Court Program evaluation placed its estimates of the benefit-to-cost ratio within ranges that depended on whether accounting or economic costs were included, and it included earnings improvements. 


\section{Appendix IV: Overview of Drug Court Program Characteristics and Participants}

This appendix provides a general description of drug court program components and describes program participants in the evaluations we reviewed. Drug court programs rely on a combination of judicial supervision and substance abuse treatment to motivate defendants' recovery. Judges preside over drug court proceedings, which are called status hearings; monitor defendants' progress with mandatory drug testing; and prescribe sanctions and rewards, as appropriate in collaboration with prosecutors, defense attorneys, treatment providers, and others. Drug court programs can vary in terms of the substance abuse treatment required. However, most programs offer a range of treatment options and generally require a minimum of about 1 year of participation before a defendant completes the program. Drug court program participants can vary across programs according to differences in eligibility requirements and jurisdictions. The participants in the drug court programs we reviewed were predominantly male, generally unemployed at the time of program entry, and had prior involvement in the criminal justice system.

\section{Drug Court Program Components}

\author{
Drug Court Program \\ Approaches
}

This section describes typical drug court program approaches, screening processes and participant eligibility requirements, completion requirements, treatment components, and sanctions.
Drug court programs generally have taken two approaches to processing cases: (1) deferred prosecution (diversion) and (2) post-adjudication. In the diversion model, the courts defer prosecution dependent on the offender's agreement to participate in the drug court program. Deferred adjudication models do not require the defendant to plead guilty. Instead the defendant enters the drug court before pleading to a charge.

Defendants who complete the treatment program are not prosecuted further or their charges are dismissed. Failure to complete the program results in prosecution for the original offense. This approach is intended to capitalize on the trauma of arrest and offers defendants the opportunity to obtain treatment and avoid the possibility of a felony conviction.

In contrast, offenders participating in a post-adjudication (post-plea) drug court program plead guilty to the charge(s) and their sentences are suspended or deferred. Upon successful completion of the program, sentences are waived and in many cases records are expunged. This approach provides an incentive for the defendant to rehabilitate because progress toward rehabilitation is factored into the sentencing 
determination. Both of these approaches provide the offender with a powerful incentive to complete the requirements of the drug court program.

Some drug court programs use both deferred prosecution and postadjudication approaches and assign defendants to an approach depending on the severity of the charge. Additionally, drug court programs may also combine aspects of these models into a hybrid, or combined, approach.

Screening Process and Participant Eligibility Criteria
Defendants reach the drug court program from different sources and at varying points in case processing. Screening defendants to determine eligibility for a drug court program generally includes screening them for legal and clinical eligibility. Initially, defendants are screened for legal eligibility, based on criminal history and current case information. Depending on the program, an assistant district or prosecuting attorney, court clerk, or drug court coordinator typically conducts the review. Criteria for legal eligibility typically include charging offense, prior convictions, pending cases, and supervision status. Drug courts generally accept defendants charged with drug possession or other nonviolent offenses such as property crimes. Some drug court programs allow defendants who have prior convictions to participate, and others do not. Federal grants administered under Title II of the 21st Century Department of Justice Appropriations Authorization Act are not supposed to be awarded to any drug court program that allows either current or past violent offenders to participate in its program. ${ }^{1}$

After defendants are determined to be legally eligible for the program, treatment providers or case managers will typically determine defendants' clinical eligibility. This can be determined through structured assessment tests, interviews, or even preliminary drug test results. While drug courts generally only accept defendants with substance abuse problems, they vary in the level of addiction or type of drug to which defendants are

\footnotetext{
${ }^{1}$ Section 2953 of Title II defines "violent offender" to mean a person who "(1) is charged with or convicted of an offense, during the course of which offense or conduct (A) the person carried, possessed, or used a firearm or dangerous weapon; (B) there occurred the death of or serious bodily injury to any person; or (C) there occurred the use of force against the person of another, without regard to whether any of the circumstances described in subparagraph (A) or (B) is an element of the offense or conduct of which or for which the person is charged or convicted; or (2) has one or more prior convictions for a felony crime of violence involving the use or attempted use of force against a person with the intent to cause death or serious bodily harm."
} 
addicted. For example, some programs do not accept defendants who only have addictions to marijuana or alcohol, while others do.

Clinical eligibility can also include factors such as medical or mental health barriers and motivation or treatment readiness. In several drug court programs in our review, the drug court judge's satisfaction with or assessment of an offender's motivation and ability to complete the program was a factor used to screen defendants.

\section{Program Completion} Requirements

Judicial Supervision and Status Hearings

Drug Testing Requirements
Drug court programs typically require defendants to complete a 1-year treatment program in order to graduate from or complete the program. Some programs impose other conditions that participants must meet in addition to treatment. These conditions could include remaining drug-free for a minimum amount of time, not being arrested for a specified period of time, maintaining employment or obtaining an educational degree or certification, or performing community service.

The central element of all drug court programs is attendance at the regularly scheduled status hearings at which the drug court judge monitors the progress of participants. Monitoring is based on treatment provider reports on such matters as drug testing and attendance at counseling sessions. The judge is to reinforce progress and address noncompliance with program requirements. The primary objectives of the status hearing are to keep the defendant in treatment and to provide continuing court supervision. More broadly, judicial supervision includes regular court appearances and direct in-court interaction with the judge, as well as scheduled case manager visits.

Monitoring participants' substance use through mandatory and frequent testing is a core component of drug court programs. Programs vary in the specific policies and procedures regarding the nature and frequency of testing. For example, in some programs in our review participants were required to call to find out whether they are required to be tested in a given period or on a randomly selected day of the week. The frequency of testing generally varied depending on the stage or phase of the program that participants were in. and is generally administered on an outpatient basis with limited inpatient treatment, as needed, to address special detoxification or relapse situations. Many of the programs operate with the philosophy that because 
Treatment services are generally divided into three phases. Detoxification, stabilization, counseling, drug education, and therapy are commonly provided during phases I and II, and in some instances, throughout the program. Other services relating to personal and educational development, job skills, and employment services are provided during phases II and III, after participants have responded to initial detoxification and stabilization. Housing, family, and medical services are frequently available throughout the program. In some instances, a fourth phase consisting primarily of aftercare-related services is provided. The objectives of drug court program treatment are generally to (1) eliminate the program participants' physical dependence on drugs through detoxification; (2) treat the defendant's craving for drugs through stabilization (referred to as rehabilitation stage) during which frequent group or individual counseling sessions are generally employed; and (3) focus on helping the defendant obtain education or job training, find a job, and remain drug free.

Drug court programs can also either directly provide or refer participants to a variety of other services and support, and they may include medical or health care, mentoring, and educational or vocational programs. The use of community-based treatment self-help groups, such as Alcoholics Anonymous (AA) and Narcotics Anonymous (NA), and aftercare programs also varies across drug court programs.

Sanctions for Noncompliance
Judges generally prescribe sanctions and rewards as appropriate in collaboration with prosecutors, defense attorneys, treatment providers, and others. Typical sanctions for program noncompliance include oral warnings from the judge; transfer to an earlier stage of the program; attendance at more frequent status hearings, treatment sessions, or drug tests; and serving jail time for several days or weeks. The approach or philosophy for how a drug court judge prescribes sanctions can vary. For example, some judges use a graduated sanctions approach, where sanctions are applied in increasing severity. Other judges may use discretion in prescribing sanctions, assessing participants' noncompliance on a case-by-case basis. 

participation in the program before completion. These criteria may include a new felony offense, multiple failures to comply with program requirements such as not attending status hearings or treatment sessions, and a pattern of positive drug tests.

Before terminating a defendant for continuing to use drugs, drug court programs generally will use an array of treatment services and available sanctions. There are no uniform standards among all programs on the number of failed drug tests and failures to attend treatment sessions that lead to a participant's termination. Drug court program judges generally make decisions to terminate a program participant on a case-by-case basis, taking into account the recommendations of others, including the treatment provider, prosecutor, and defense counsel. Relapses are expected, and the extent to which noncompliance results in terminations varies from program to program. Once a defendant is terminated, he or she is usually referred for adjudication or sentencing.

\section{Drug Court Program Participants}

All of the evaluations we reviewed reported some basic substance use or demographic data about the drug court program participants. However, not every evaluation reported the same types of information or provided equivalent levels of detail.

\author{
Participants' Substance \\ Use Characteristics
}

The types of drugs participants reported using varied. Cocaine (crack or powder) was selected by the highest percentage of participants as the primary drug of choice in most of the programs reporting these data. ${ }^{2}$ However, in Baltimore, 77 percent reported heroin was primary drug of choice, whereas 43 percent of participants in the Tacoma, Washington, Breaking the Cycle program reported using methamphetamine, suggesting regional differences in drugs of choice. Participants in evaluations we reviewed did not always report "hard" drugs as their primary substances of choice. In several evaluations we reviewed, participants reported that alcohol or marijuana was their primary drug of choice. For example, in Chester County, 47 percent of participants reported marijuana, and

\footnotetext{
${ }^{2}$ The evaluations used different measures to report drug use, such as "primary drug of choice," "used in the past 30 days," or "used in the 90 days before program entry." Participants may indicate using more than one substance.
} 
84 percent of participants in Maricopa County reported alcohol as primary drugs of choice.

Selected Demographic and Socioeconomic Characteristics
The participants in the drug court programs we reviewed were generally in their early 30s, predominantly male, and generally unemployed at the time of program entry. Participants' average age at program entry ranged from 24 years (in a misdemeanor-only drug court program in New Castle County, Delaware) to 36 years (in the Baltimore City Drug Treatment Court). ${ }^{3}$ In the majority of these evaluations, participants were, on average, between 30 and 35 .

Participants were also predominantly male. The percentage of male defendants participating in drug court programs we reviewed ranged from 46 percent in Bakersfield, California, to 88 percent in the Jacksonville, Florida, Breaking the Cycle program. Generally, however, about 60 to 80 percent of participants in these programs were male, which corresponds to other reviews estimating that across multiple drug court programs about 70 percent of participants are male.

In about half of the evaluations we reviewed that reported data about participants' race or ethnicity, the majority (50 percent or more) of the participants were white. However, in some programs, most participants (that is, over 75 percent of the sample) were predominantly of one racial or ethnic background. For example, in five of the six Washington state drug court programs, between 79 and 92 percent of participants were white; and in the Baltimore and Washington, D.C., drug court programs, between 89 and 99 percent of participants were black. Some other programs reported that the participants were not predominantly of one racial or ethnic background. For example, in Los Angeles County, 23 percent of participants were white, 30 percent black, and 43 percent Hispanic or other.

Drug court participants in the evaluations we reviewed that reported data on employment and educational status were generally unemployed with less than a high school education at program entry. Between 16 to 82 percent of participants were employed at the time of entry into the

${ }^{3}$ Most evaluations we reviewed reported average age. However, some reported median age, which ranged from 23 to 34 years. 

data, less than half of the participants were employed at the time of entry into the drug court program. Similarly, in evaluations that reported information about participants' educational status, 24 to 75 percent of participants reported that they had less than a high school education at the time of entry into the program. Generally, about 30 to 60 percent had less than a high school education at the time of entry into the program. For example, in the New York State evaluation, across the programs, the median percentage of participants who have received a general equivalency diploma (GED) or high school diploma is 45 percent; similarly, the median percentage employed or in school is 34 percent. in evaluations we reviewed, was generally considerable. ${ }^{5}$ Most participants were not first-time offenders. However the types and severity of involvement varied. In the evaluations that reported these data, the average number of prior arrests (of any kind) ranged from about 1 to about 13 per participant over different time periods, ranging from 1 to 5 years before entry into the drug court program. Additionally, in the six New York State drug court programs, the percent of participants with prior convictions ranged from 19 percent in Queens, which says it does not accept participants with prior felony convictions, to 69 percent in Syracuse. However, the researchers note that less than one-third of prior convictions in all courts were drug-related, which indicates that participants are involved in a wider range of criminal activity. This description of drug court participants' criminal justice system involvement in the evaluations we reviewed was similar to descriptions reported by other sources. For example, the Drug Court Clearinghouse and Technical Assistance Project's 2001 survey of responding adult drug court programs

\footnotetext{
${ }^{4}$ The 82 percent employed occurred in the Las Cruces Municipal DWI Court, the only DWI court included in our review.

${ }^{5}$ Most evaluations reported some information on criminal justice system involvement. However, the measures and types of information reported varied. For example, some evaluations reported arrests, others convictions; some reported the average number of prior events - either arrest or conviction-while others reported the percent of participants with at least one event.
} 
Appendix IV: Overview of Drug Court

Program Characteristics and Participants

reported that 9 percent of participants had no prior felony convictions and 56 percent had been previously incarcerated. 


\section{Appendix V: Drug Court Programs Are Associated with Recidivism Reductions}

In most of the evaluations we reviewed, adult drug court programs led to statistically significant recidivism reductions during periods of time that generally corresponded to the length of the drug court program-that is, within-program. ${ }^{1}$ For the remaining programs, evaluations showed no significant differences in recidivism. Our analysis of the evaluations showed lower percentages of drug court program participants than comparison group members were rearrested or reconvicted. Program participants also had fewer recidivism events-that is, incidents of rearrests or reconvictions-and a longer time until rearrest or reconviction than comparison group participants. Recidivism reductions were observed for any felony offense and for drug offenses, whether they were felonies or misdemeanors. However, the evaluations did not provide conclusive evidence that specific drug court program components, such as the judge's characteristics or behavior, the amount of treatment received, the level of supervision provided, and the sanctions for noncompliance with program requirements, affect participants' within-program recidivism. In most of the programs that reported post-program data, recidivism reductions occurred for some period of time after participants completed the drug court program.

Drug Court Programs Led to WithinProgram Recidivism Reductions
The 27 evaluations we reviewed provided within-program recidivism comparisons between drug court program participants and an appropriate control or comparison group of non-drug court defendants in 23 different drug court programs. Regardless of the type of comparison group used, within-program recidivism reductions occurred for various measures of recidivism, such as rearrests and reconvictions, and prevailed across different types of offenses. ${ }^{2}$ Less clear, however, was the effect that certain drug court program components, such as treatment options or sanctions, had on participants' recidivism outcomes.

\footnotetext{
${ }^{1}$ We use within-program to refer to the period of time that all individuals who are enrolled are expected to be participating in the drug court program.

${ }^{2}$ Appendix II presents details on the research designs and comparison groups used in the evaluations we reviewed.
} 


\section{Drug Court Programs Were Associated with Lower Rearrest Rates for Program Participants}

Drug court programs included in our review were associated with reductions in overall rearrest rates - that is, the percentage of a group arrested for any new offense (felony or misdemeanor) in a given period of time. Thirteen drug court programs reported overall rearrest data. ${ }^{3}$ Ten of these found statistically significant reductions in overall rearrest rates for drug court program participants. ${ }^{4}$ Across studies showing rearrest reductions, rates of drug court program participants generally ranged from about 10 to 30 percentage points below those of the comparison group. Table 7 shows these differences in rearrest rates by the length of the time frame covered.

\footnotetext{
${ }^{3}$ The evaluations we reviewed provided comparative arrest data for drug court program participants and comparison group members for 13 drug court programs. In 1 drug court program - the D.C. Superior Court—data were available for two dockets, or types of drug court program interventions, to which defendants were assigned.

${ }^{4}$ Rearrests, as well as reconvictions, do not measure all re-offending, as every offense or violation does not lead to an arrest.
} 
Table 7: Differences in Overall Rearrest Rates between Drug Court Program Participants and Comparison Group Members

\begin{tabular}{|c|c|c|c|}
\hline \multirow[b]{2}{*}{ Drug court program } & \multirow[b]{2}{*}{$\begin{array}{l}\text { Comparison group used in program } \\
\text { evaluation }\end{array}$} & \multicolumn{2}{|c|}{$\begin{array}{c}\text { Percentage point difference, time frame } \\
\text { covered }\end{array}$} \\
\hline & & $\begin{array}{r}\text { Up to } 1 \text { year after } \\
\text { entry }\end{array}$ & $\begin{array}{r}\text { Up to } 2 \text { years after } \\
\text { entry }\end{array}$ \\
\hline \multicolumn{4}{|l|}{ Significant reported reductions } \\
\hline Baltimore City Drug Treatment Court & Randomly assigned similar defendants & $-16 \%{ }^{a}$ & $-15 \%{ }^{a}$ \\
\hline $\begin{array}{l}\text { Breaking the Cycle Program, } \\
\text { Birmingham }^{b}\end{array}$ & Historical-arrestees & $-35^{a}$ & \\
\hline Breaking the Cycle Program, Tacoma & Historical-arrestees & $-15^{\mathrm{a}}$ & \\
\hline $\begin{array}{l}\text { D.C. Superior Court Drug Intervention } \\
\text { Program, sanctions docket }\end{array}$ & Randomly assigned similar defendants & $-8^{a}$ & \\
\hline Douglas County Drug Court & $\begin{array}{l}\text { Contemporaneous-traditionally } \\
\text { adjudicated offenders }\end{array}$ & $-19^{a}$ & \\
\hline Jackson County Drug Court & Historical-arrestees & & $-20^{a}$ \\
\hline Kentucky Drug Court Programs & $\begin{array}{l}\text { Contemporaneous-assessed } \\
\text { offenders, combined felony and } \\
\text { misdemeanor charge or conviction }\end{array}$ & $-17^{\mathrm{a}}$ & $-4^{a}$ \\
\hline $\begin{array}{l}\text { Los Angeles County Drug Court } \\
\text { Program }\end{array}$ & Contemporaneous-probationers & $-27^{a}$ & \\
\hline $\begin{array}{l}\text { Maricopa County First Time Drug } \\
\text { Offender Program }\end{array}$ & $\begin{array}{l}\text { Randomly assigned similar } \\
\text { probationers_-results for combined } \\
\text { groups }\end{array}$ & -1 & $-11^{a}(3$ yrs $)$ \\
\hline Orange County Drug Court Program & Contemporaneous-probationers & $-10^{a}$ & \\
\hline \multicolumn{4}{|l|}{ Nonsignificant reported differences } \\
\hline $\begin{array}{l}\text { Breaking the Cycle Program, } \\
\text { Jacksonville }^{\text {b }}\end{array}$ & Historical-arrestees & 7 & \\
\hline $\begin{array}{l}\text { D.C. Superior Court Drug Intervention } \\
\text { Program, treatment docket }\end{array}$ & Randomly assigned similar defendants & -1 & \\
\hline Escambia County Drug Court & Historical-arrestees & & -10 \\
\hline
\end{tabular}

Source: GAO analysis of drug court program evaluations.

Note: When the difference is negative, that indicates that a drug court program reduced rearrests; when it is positive, that indicates that drug court program participants had higher rearrest rates than their comparison group. Nonsignificant differences may be positive or negative, but the absence of a statistical difference is interpreted to mean that there is no difference in recidivism between the drug court program and comparison group.

${ }^{a}$ The difference was reported to be statistically significant.

${ }^{\mathrm{b}}$ According to the principal researcher of the evaluation, the Breaking the Cycle program is technically not considered to be a drug court program. However, we included the program in our review because it incorporates several of the basic drug court program components, such as drug testing and access to treatment services.

${ }^{\circ}$ While these defendants consisted primarily of those arrested during the time the drug court program was in operation (a contemporaneous comparison), some individuals who were arrested in the 3 months prior to the start of the drug court program were included. 
Not All Drug Court Programs Reduced Recidivism for All Offenses
In two drug court programs (Breaking the Cycle program in Jacksonville and the D.C. Superior Court treatment docket), the program did not lead to significant differences in overall within-program recidivism. The absence of a significant difference suggests that these drug court programs did not necessarily lead to recidivism reductions. In one of these programs (the D.C. Superior Court), two types of drug court program interventions were examined-(1) a treatment docket, consisting of an intensive treatment-only intervention and (2) a sanctions docket, consisting of an intervention that combined referrals to treatment with graduated sanctions. The evaluation showed statistically significant reduction in rearrests for the sanctions docket. However, results for the treatment docket (treatment alone) were not statistically significant. A third drug court program in Escambia County showed mixed results. The drug court program showed no differences for overall rearrest rates (both felonies and misdemeanors) but showed a significant reduction in felony rearrest rates.
Drug Court Programs Were Associated with Lower Reconviction Rates for Program Participants
The evaluations we reviewed showed lower reconviction rates-the percentage of a group convicted for a new offense in a given period of time-for drug court program participants than for comparison group members. ${ }^{5}$ Almost all of the programs (10 of 12) with these data reported a statistically significant reduction in reconviction rates for drug court program participants in one of the time frames covered. The two programs that did not show statistically significant reductions in reported results in a direction of reconviction reduction, but not at a statistically significant level. Table 8 displays the differences in reconviction rates between drug court participants and comparison group members after up to 1 year and after 2 to 3 years of entry into their respective programs.

${ }^{5}$ The evaluations we reviewed measured reconviction rates during periods of up to 3 years after entry into either the drug court program or the comparison group. 
Table 8: Differences in Reconviction Rates between Drug Court Program Participants and Comparison Group Members

\begin{tabular}{|c|c|c|c|}
\hline \multirow[b]{2}{*}{ Drug court program } & \multirow[b]{2}{*}{$\begin{array}{l}\text { Comparison group used } \\
\text { in program evaluation }\end{array}$} & \multicolumn{2}{|c|}{$\begin{array}{l}\text { Percentage point difference, time frame } \\
\text { covered }\end{array}$} \\
\hline & & $\begin{array}{l}\text { Up to } 1 \text { year } \\
\text { after entry }\end{array}$ & $\begin{array}{l}2 \text { to } 3 \text { years } \\
\text { after entry }\end{array}$ \\
\hline \multicolumn{4}{|l|}{ Significant reported reductions } \\
\hline Bronx Treatment Court $^{\mathrm{a}}$ & Historical-eligible arrestees & $-9 \%{ }^{b}$ & $-15 \%{ }^{\mathrm{b}}(3 \mathrm{yrs})$ \\
\hline Brooklyn Treatment Court $^{\mathrm{a}}$ & Contemporaneous-eligible arrestees & $-10^{\mathrm{b}}$ & $-14^{\mathrm{b}}(3 \mathrm{yrs})$ \\
\hline Douglas County Drug Court & $\begin{array}{l}\text { Contemporaneous-traditionally adjudicated } \\
\text { offenders }^{c}\end{array}$ & $-8^{b}$ & \\
\hline Kentucky Drug Court Programs & $\begin{array}{l}\text { Contemporaneous-assessed offenders, } \\
\text { combined felony and misdemeanor charge } \\
\text { or conviction }\end{array}$ & $-15^{b}$ & $-5^{b}$ \\
\hline $\begin{array}{l}\text { Maricopa County First Time Drug } \\
\text { Offender Program }\end{array}$ & $\begin{array}{l}\text { Randomly assigned similar probationers- } \\
\text { results for combined groups }\end{array}$ & -3 & $-6^{b}$ \\
\hline Queens Treatment Court ${ }^{\mathrm{a}}$ & Historical_eligible arrestees & $-21^{\mathrm{b}}$ & $-13^{\mathrm{b}}$ (3 yrs) \\
\hline Rochester Drug Treatment Court ${ }^{\mathrm{a}}$ & $\begin{array}{l}\text { Contemporaneous-eligible arrestees who } \\
\text { were not arraigned before a judge } \\
\text { supportive of the program }\end{array}$ & $-10^{b}$ & $-10^{\mathrm{b}}$ (3 yrs) \\
\hline $\begin{array}{l}\text { Suffolk County Drug Treatment } \\
\text { Court }^{\mathrm{a}}\end{array}$ & Historical_eligible arrestees & $-21^{b}$ & $-25^{\mathrm{b}}$ (3 yrs) \\
\hline $\begin{array}{l}\text { Syracuse Community Treatment } \\
\text { Court }^{\mathrm{a}}\end{array}$ & Historical_eligible arrestees & $-16^{b}$ & $-14^{\mathrm{b}}(2 \mathrm{yrs})$ \\
\hline $\begin{array}{l}\text { Washington State Drug Court } \\
\text { Program, five counties combined }\end{array}$ & Historical-arrestees & & $-6^{b}$ \\
\hline \multicolumn{4}{|l|}{ Nonsignificant reported reductions } \\
\hline $\begin{array}{l}\text { Baltimore City Drug Treatment } \\
\text { Court }\end{array}$ & Randomly assigned similar defendants & -5 & \\
\hline $\begin{array}{l}\text { Washington State Drug Court } \\
\text { Program, King County }\end{array}$ & Historical-arrestees & & -2 \\
\hline
\end{tabular}

Source: GAO analysis of drug court program evaluations.

Note: When the difference is negative, that indicates that a drug court program reduced reconvictions when it is positive, that indicates that drug court program participants had higher reconviction rates than the comparison group members. Nonsignificant differences may be positive or negative, but the absence of a statistical difference is interpreted to mean that there is no difference in recidivism between the drug court program and comparison group.

${ }^{\text {a } T h e ~ d a t a ~ f o r ~ t h e s e ~ s i x ~ d r u g ~ c o u r t ~ p r o g r a m s ~ w e r e ~ p r o v i d e d ~ f r o m ~ o n e ~ m u l t i s i t e ~ e v a l u a t i o n ~ o f ~ N e w ~ Y o r k ~}$ state drug court programs.

${ }^{\mathrm{b}}$ The difference was reported to be statistically significant.

${ }^{c}$ While these defendants consisted primarily of those arrested during the time the drug court program was in operation (a contemporaneous comparison), some individuals who were arrested in the 3 months prior to the start of the drug court program were included. 
The significant differences in reconviction rates between drug court participants and comparison group members ranged from 8 to 21 percentage points within 1 year of entry into the drug court program. For the eight drug court programs in which follow-up data were provided for more than 1 year, statistically significant differences in reconviction rates ranged from between 5 and 25 percentage points. In five of these drug court programs, the differences in reconvictions generally increased or remained about the same as the length of the follow-up period increased.

Drug Court Participants Had Fewer Recidivism Events and Longer Times to First Recidivism Event than Comparison Group Members Did
Consistent with reducing the percentage of participants rearrested or reconvicted within a given period, drug court program effects may occur by reducing the number of recidivism events-the number of arrests or convictions within a particular period - that participants commit and by increasing the time until participants commit an offense leading to an arrest or reconviction. In 8 of 12 programs, drug court participants had fewer rearrests and in 7 of 9 programs they had fewer reconvictions than comparison group members. Per 100 drug court program and comparison group participants, drug court program participants had between 9 and 90 fewer arrests during the program, or between 18 and 89 fewer convictions during the program, depending on the recidivism measure reported.

Drug court program participants also generally had longer times to first arrest or conviction than comparison group members. In 11 of 16 programs in which the time to first event was reported, drug court program participants had longer times to the first recidivism event.

\section{Recidivism Reductions Were Observed for Different Offense Types}

Evidence showed recidivism reductions for different types of offenses, specifically for felonies and drug offenses, which may indicate decreased involvement in substance abuse. In almost all (9 of 12) of the programs that reported data on felony offense recidivism rates (either rearrest or reconviction), drug court participants had lower felony recidivism rates or fewer recidivism events. Similarly, in 11 of 14 of the programs that reported data on drug offense recidivism, drug court participants were either rearrested or reconvicted for drug offenses at lower rates.

One drug court program that found no significant reduction in rearrests did find a reduction in specific offense types. Specifically, the evaluation of the drug court program in Escambia County found that there were no significant differences in overall rearrests between drug court participants 

cautioned against interpreting such a large reduction in felony rearrests as indicative of the amount of a reduction that could be expected from the drug court program were it to be implemented for a larger numbers of defendants.

Drug Court Program

Components Were Infrequently Evaluated and Results Were Inconclusive

Effects of the Role of the Judge

Effects of Substance Abuse Treatment and Sanctions Imposed
A limited number of evaluations reported information about whether specific drug court program components affect participants' recidivism, and their results were mixed. Drug court program judges, the treatment programs prescribed for participants, and the sanctions used to enforce compliance with drug court program procedures are three of the basic components of drug court programs. Two evaluations that we reviewed provided data on the effects of treatment and supervision on drug court program participants' within-program recidivism outcomes.

None of the evaluations we reviewed explicitly studied the effect of the judge - considered to be a critical component of a drug court programon participants' within-program recidivism.

In evaluations of two drug court programs, the effects of two basic components of drug courts-substance abuse treatment and sanctionswere assessed, and their results varied. The specific types of substance abuse treatment provided to participants differ among programs. In general, treatment, depending on the needs of the participant, can include detoxification, individual and group counseling on an outpatient basis, substance use prevention education, as well as other health, educational, vocational, or medical services. Similarly, the types and severity of sanctions that judges use to enforce compliance with program requirements vary. These sanctions can include writing an essay, observing drug court proceedings for several days from the jury box, community service, or short jail stays. Drug court programs may use a graduated sanctions approach, where successive infractions are met with increasingly severe sanctions. In other programs, judges may have discretion to apply sanctions, as needed, according to the specifics of the case.

To assess the effect of treatment, two evaluations examined recidivism differences between drug court program participants who attended more treatment sessions than other participants. In one of the two evaluations 
that provided the strongest designs for measuring treatment effects-the evaluation of the Baltimore City Drug Treatment Court-treatment contributed to reductions in recidivism. However, in the other-the evaluation of the D.C. Superior Court treatment docket-there were no differences between the treatment docket and the control group, who were assigned to a standard docket, consisting of some level of supervision, monitoring, and access to services. ${ }^{6}$ In both of these evaluations, drug court program participants and control group members participated in treatment, but the drug court program participants received more treatment and were engaged in a more structured treatment regime than were control group members.

Findings from these two evaluations also indicate that treatment requirements combined with supervision and sanctioning contribute the most to recidivism reductions. While the evaluation of the Baltimore City Drug Treatment Court measured a distinct difference between those who participated more heavily in treatment, it also found that those who received treatment combined with supervision had the lowest recidivism rates. The D.C. Superior Court sanctions docket, which also combined judicial supervision with treatment, specifically engaged participants in a program in which judges applied an established set of graduated sanctions for failing to comply with drug court program requirements. The sanctions docket led to fewer rearrests for participants as compared with the control group assigned to the standard docket. The Baltimore City and D.C. Superior Court sanctions docket results support the contention that treatment requirements that are combined with supervision and sanctioning contribute the most to recidivism reductions.

\footnotetext{
${ }^{6}$ The evaluation notes that recidivism analysis does not test the effect of a strong treatment program because the treatment docket experienced substantial operational problems, including closure because of building structural problems and financial problems that precluded certain types of services from being delivered.
} 
Limited Evidence Indicates That Recidivism Reductions Endure
While fewer evaluations reported post-program, rather than withinprogram, recidivism results, those that did indicate that recidivism reductions endure beyond the time that participants are engaged in the program. ${ }^{7}$ Evaluations we reviewed reported post-program recidivism for longer periods for 17 drug court programs. In 13 of these 17 programs, drug court program participants had lower rearrest or reconviction rates than comparison group members. One evaluation of 6 programs defined explicit post-program periods of about 1 year, and drug court program participants had lower recidivism than comparison group members of 5 of the 6 programs. Among drug court program participants, graduates had lower post-program recidivism than dropouts.

\author{
Lower Rearrest and \\ Reconviction Rates
}

Significantly lower rearrest and reconviction rates were reported for participants in 13 of the 17 drug court programs that reported these data. As shown in table 9 , for 6 drug court programs reporting significant reductions, the differences in rearrest rates between drug court program participants and comparison group members ranged between 4 to 20 percentage points. The evaluation of the Multnomah County drug court program reported only the mean number of arrests (recidivism events), but it also showed post-program reduction in recidivism using this measure. For the 9 drug court programs reporting significant reductions, the differences in reconviction rates between drug court participants and comparison group members ranged from 5 to 25 percentage points.

\footnotetext{
${ }^{7}$ We generally use the term post-program to refer to some period of time after drug court participants and comparison group members completed their respective programs. However, for some drug court programs, the evaluations measured recidivism for a period after participants left the program. These represent explicit post-program periods. Postprogram recidivism outcomes were generally observed for no longer than 1 year. Hence, it is not possible to determine whether the differences in recidivism observed between drug court program participants and comparison groups would persist.
} 
Table 9: Differences in Rearrest and Reconviction Rates, over Longer Time Periods, between Drug Court Program Participants and Comparison Group Members

\begin{tabular}{|c|c|c|c|c|}
\hline \multirow[b]{2}{*}{ Drug court program } & \multicolumn{4}{|c|}{ Recidivism measure, percentage point difference } \\
\hline & Rearrested & $\begin{array}{r}\text { Time frame } \\
\text { covered after entry }\end{array}$ & Reconvicted & $\begin{array}{r}\text { Time frame } \\
\text { covered after entry }\end{array}$ \\
\hline \multicolumn{5}{|l|}{ Significant reported reductions } \\
\hline Baltimore City Drug Treatment Court & $-15^{\mathrm{a}}$ & 2 years & & \\
\hline Bronx Treatment Court $^{\mathrm{b}}$ & & & $-15^{a}$ & Up to 4 years \\
\hline Brooklyn Treatment Court $^{b}$ & & & $-14^{\mathrm{a}}$ & Up to 4 years \\
\hline Jackson County Drug Court & $-20^{\mathrm{a}}$ & 2 years & & \\
\hline Kentucky Drug Court Programs & $-4^{a}$ & 1 year post-program & $-5^{\mathrm{a}}$ & 1 year post-program \\
\hline $\begin{array}{l}\text { Maricopa County First Time Drug Offender } \\
\text { Program }\end{array}$ & $-11^{\mathrm{a}}$ & 3 years & $-6^{\mathrm{a}}$ & 3 years \\
\hline $\begin{array}{l}\text { Multnomah County STOP Drug Diversion } \\
\text { Program }^{c}\end{array}$ & $-0.94^{a}$ & 2 years & & \\
\hline North Carolina Drug Treatment Court & $-10^{a}$ & 1 year post program & & \\
\hline Queens Treatment Court $^{\mathrm{b}}$ & & & $-13^{\mathrm{a}}$ & Up to 4 years \\
\hline Rochester Drug Treatment Court $^{\mathrm{b}}$ & & & $-10^{\mathrm{a}}$ & Up to 4 years \\
\hline Suffolk County Drug Treatment Court $^{\mathrm{b}}$ & & & $-25^{a}$ & Up to 4 years \\
\hline Syracuse Community Treatment Court ${ }^{\mathrm{b}}$ & & & $-14^{\mathrm{a}}$ & Up to 4 years \\
\hline $\begin{array}{l}\text { Washington State Drug Court Program, five } \\
\text { counties combined }\end{array}$ & & & $-6^{a}$ & 3 years \\
\hline \multicolumn{5}{|c|}{ Nonsignificant reported differences or significant increase } \\
\hline Clark County Drug Court & & & $10^{\mathrm{a}}$ & $\begin{array}{l}2 \text { years post } \\
\text { program }\end{array}$ \\
\hline Escambia County Drug Court $^{\mathrm{d}}$ & -10 & 2 years & & \\
\hline Southern San Mateo County Drug Court & 2 & 2 years & & \\
\hline $\begin{array}{l}\text { Washington State Drug Court Program, King } \\
\text { County }\end{array}$ & & & -2 & 3 years \\
\hline
\end{tabular}

Source: GAO analysis of drug court program evaluations

Note: When the difference is negative, that indicates that a drug court program reduced recidivism; when it is positive, that indicates that drug court program participants had higher recidivism rates than members of their comparison group.

${ }^{a}$ The difference was reported to be statistically significant.

${ }^{\mathrm{b}}$ The data for these six drug court programs were provided from one multisite evaluation of New York state drug court programs.

${ }^{\circ}$ The Multnomah County results show differences in the average number of arrests only.

${ }^{d}$ Escambia County drug court showed a significant reduction in felony rearrest rates but showed no significant difference for overall rearrest rates (both felonies and misdemeanors). 
Evidence that a gap in post-program recidivism can increase over time comes from the evaluation of the Maricopa County drug court program. In Maricopa County, there were no reported differences in recidivism (specifically rearrest rates) during the 1-year within-program time frame. However, a 3-year follow-up evaluation found a significant (11 percentage point) difference in rearrest rates between the drug court program participants and control group members. The difference arose largely from an increase in the percentage of control group members that had been rearrested by the end of the 3-year follow-up; 32 percent of the control group were rearrested by 1 year, but by 3 years, 44 percent were rearrested. For the drug court participants, 31 percent had been rearrested at the end of 1 year, but only an additional 2 percent of the sample were rearrested within 3 years.

Recidivism Reductions in Explicit Post-Program Periods
For the six programs with explicit post-program periods, participants had significantly lower recidivism than comparison group members in all but one program, as shown in table 10. 
Table 10: Post-Program Differences in Recidivism in Six New York State Drug Court Programs

\begin{tabular}{|c|c|c|}
\hline New York state drug court program & Comparison group used in evaluation & $\begin{array}{l}\text { Percentage point difference in } \\
\text { recidivism, 1-year post-program }\end{array}$ \\
\hline \multicolumn{3}{|l|}{ Significant reported reductions } \\
\hline Bronx Treatment Court & $\begin{array}{l}\text { Historical arrestees: eligible defendants } \\
\text { arrested in the Bronx prior to the start of the } \\
\text { drug court program. }\end{array}$ & $-13 \%{ }^{a}$ \\
\hline Brooklyn Treatment Court & $\begin{array}{l}\text { Contemporaneous: eligible drug felony } \\
\text { defendants arrested in Brooklyn but not } \\
\text { screened in the drug court, primarily } \\
\text { because they were arrested within one of } \\
\text { the two geographic zones that were } \\
\text { ineligible to send defendants to the drug } \\
\text { court program. }\end{array}$ & $-6^{b}$ \\
\hline Queens Treatment Court & $\begin{array}{l}\text { Historical arrestees: eligible defendants } \\
\text { arrested in Queens in the year prior to the } \\
\text { drug court program's implementation. }\end{array}$ & $-13^{\mathrm{a}}$ \\
\hline Rochester Drug Treatment Court & $\begin{array}{l}\text { Contemporaneous arrestees: eligible } \\
\text { defendants arrested in Rochester during } \\
\text { the same period of time as the drug court } \\
\text { was in operation but who were not } \\
\text { arraigned before a judge supportive of the } \\
\text { program. }\end{array}$ & $-7^{\mathrm{b}}$ \\
\hline Suffolk County Drug Treatment Court & $\begin{array}{l}\text { Historical arrestees: eligible defendants } \\
\text { arrested in Suffolk County in the year prior } \\
\text { to the start of the drug court program. }\end{array}$ & $-9^{b}$ \\
\hline \multicolumn{3}{|l|}{ Nonsignificant reported reduction } \\
\hline Syracuse Community Treatment Court & $\begin{array}{l}\text { Historical arrestees: eligible defendants } \\
\text { arrested in Syracuse City in the year prior } \\
\text { to the start of the drug court program. }\end{array}$ & -7 \\
\hline & 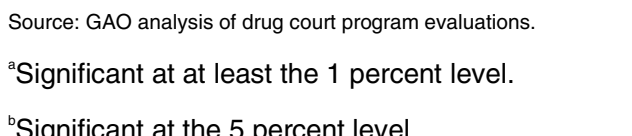 & \\
\hline
\end{tabular}

In five of the six New York state drug court programs, drug court participants had significantly lower post-program recidivism rates than did their comparison group members. The differences in recidivism, measured by the percentage with a new arrest leading to a conviction for 1 year after drug court participants left the program, ranged from 6 to 13 percentage points, as shown in table 10. These findings indicate that for some programs at least, drug court programs can be effective at reducing criminal behavior while participants are engaged in the program and after they leave the program. The evaluation of these drug court programs reports that there is evidence that the effects of drug court programs on recidivism do not diminish over time, but because the post-program period 
was only 1 year, that improved understanding of the longer-run effects of drug courts on recidivism would benefit from additional research that extends the post-program follow-up time frames.

\section{Graduates Had Lower Post-Program Recidivism than Dropouts}

Several evaluations compared post-program recidivism outcomes for drug court program graduates with those of dropouts-those participants who were terminated from the program either by their withdrawal or by sanctioning. These evaluations show that the post-program recidivism differences observed between all drug court program and comparison group participants arise primarily from the large recidivism differences between drug court program graduates and dropouts. Evaluations that reported these comparisons showed large differences in the recidivism rates of drug court program graduates compared with both dropouts and comparison group members. For example, in three New York state drug court programs, dropouts were four to seven times more likely to be reconvicted than graduates. Specifically, in the Bronx Treatment Court, 29 percent of dropouts were reconvicted during the first year after the program as compared with only 4 percent of graduates. In addition, the post-program recidivism rates of dropouts were generally no different from (or in some cases greater than) the recidivism rates of comparison group members. 


\section{Appendix VI: Limited and Mixed Evidence on Drug Court Programs' Impacts on Substance Use Relapse}

Evidence about the effectiveness of drug court programs in reducing participants' substance use relapse is limited and mixed. The evidence on substance use relapse outcomes is limited to data available from eight drug court programs included in our review. The data include drug test results and self-reported drug use; both measures were reported for some programs. Drug test results generally showed significant reductions in use during participation in the program, while self-reported results generally showed no significant reductions in use.

Limited Evidence on Drug Court Programs' Impact on Substance Use Relapse
The evidence on substance use relapse outcomes is limited to data available from eight drug court programs. ${ }^{1}$ Evaluations in these eight drug court programs used two different measures of substance use-drug test results and self-reported use-to compare relapse between participants and comparison group members. Three of these programs used both measures to assess relapse. Table 11 shows the comparison group used in the programs' evaluation and the results for the eight drug court programs that presented substance use relapse data, grouped by the type of drug use measure used.

\footnotetext{
${ }^{1}$ Some other evaluations we reviewed provided descriptive data on drug court program participants' substance use while they were engaged in the drug court program, but these evaluations did not assess substance use relapse as an outcome by comparing the outcomes of participants against those of a comparison group.
} 
Appendix VI: Limited and Mixed Evidence on

Drug Court Programs' Impacts on Substance

Use Relapse

Table 11: Substance Use Relapse Results, by Different Measures of Use, for Programs GAO Reviewed

\begin{tabular}{|c|c|c|}
\hline Drug court program & $\begin{array}{l}\text { Comparison group used in } \\
\text { evaluation of program }\end{array}$ & Results of substance use relapse \\
\hline \multicolumn{3}{|l|}{ Drug tests } \\
\hline Chester County Drug Court & Historical-probationers & $\begin{array}{l}\text { Reduction within-program: There were } \\
\text { significantly lower rates of positive drug test } \\
\text { results for drug court program participants. }\end{array}$ \\
\hline $\begin{array}{l}\text { Maricopa County First Time Drug Offender } \\
\text { Program }\end{array}$ & $\begin{array}{l}\text { All individuals identified as eligible for the } \\
\text { drug court program were randomly } \\
\text { assigned to one of three study groups at } \\
\text { the time of their initial probation } \\
\text { assignment. The three study groups were: } \\
\text { (1) probation with no testing; } \\
\text { (2) probation with low-rate (monthly) drug } \\
\text { testing; and } \\
\text { (3) probation with high-rate (biweekly) drug } \\
\text { testing. }\end{array}$ & $\begin{array}{l}\text { No reduction within-program: Among all } \\
\text { drug court and probation control group } \\
\text { members, there were no significant } \\
\text { differences in the percent that tested } \\
\text { positive for any drug. However, significantly } \\
\text { lower percentages of drug court } \\
\text { participants tested positive for cocaine. } \\
\text { Significantly higher percentages of drug } \\
\text { court participants tested positive for } \\
\text { marijuana, valium, and alcohol. }\end{array}$ \\
\hline
\end{tabular}

\section{Self-reported drug use}

Breaking the Cycle Program, Birmingham Historical-arrestees

Reduction within-program: Participants reported lower use of any drug during the past 30 days and significantly lower use of stronger drugs (such as cocaine and heroin).

Breaking the Cycle Program, Jacksonville Historical-arrestees

Reduction within-program: Participants reported significantly lower use during the past 30 days of any drug, lower heavy drug use (defined as 16 or more days of illegal drug use), and lower marijuana use. They reported no differences in use of stronger drugs (such as cocaine).

Breaking the Cycle Program, Tacoma Historical-arrestees

No reduction within-program: There was no difference in self-reported drug use on rates or types of drugs.

\begin{tabular}{ll}
\hline Both drug tests and self-reported use & \\
\hline D.C. Superior Court Drug Intervention & Randomly assigned eligible defendants \\
Program, sanctions docket &
\end{tabular}

Reduction within-program: Drug tests were taken during the final month of the program-that is, within-program. Twentyseven percent of drug court participants tested drug-free in all drug tests compared with 11 percent of the control group. Fiftythree percent of drug court participants had a "bad test outcome" (negative result, missed test, or tampered result) as compared with 71 percent of the control group.

No reduction post-program: There were no differences in self-reported drug use that occurred during the year after sentencing. 
Appendix VI: Limited and Mixed Evidence on

Drug Court Programs' Impacts on Substance

Use Relapse

\begin{tabular}{|c|c|c|}
\hline Drug court program & $\begin{array}{l}\text { Comparison group used in } \\
\text { evaluation of program }\end{array}$ & Results of substance use relapse \\
\hline \multirow[t]{2}{*}{$\begin{array}{l}\text { D.C. Superior Court Drug Intervention } \\
\text { Program, treatment docket }\end{array}$} & Randomly assigned eligible defendants & $\begin{array}{l}\text { Reduction within-program: Drug tests } \\
\text { were taken during the final month of the } \\
\text { program. Twenty-two percent of drug court } \\
\text { participants tested drug-free in all drug } \\
\text { tests as compared with } 11 \text { percent of the } \\
\text { control group. Also, } 64 \text { percent of the drug } \\
\text { court participants had "bad test outcome" } \\
\text { (negative result, missed test, or tampered } \\
\text { result) as compared with } 71 \text { percent of the } \\
\text { control group. }\end{array}$ \\
\hline & & $\begin{array}{l}\text { No reduction post-program: There were } \\
\text { no differences in self-reported drug use that } \\
\text { occurred during the year after sentencing. }\end{array}$ \\
\hline New Castle County Drug Court Program & $\begin{array}{l}\text { Drug court program participants who were } \\
\text { randomly assigned to biweekly versus "as } \\
\text { needed" judicial status hearings }\end{array}$ & $\begin{array}{l}\text { Reduction within-program for } \\
\text { subgroups: There were significant } \\
\text { reductions in positive drug test results for } \\
\text { participants with mental health problems } \\
\text { and prior treatment who were assigned to } \\
\text { the biweekly condition compared with those } \\
\text { assigned to the "as-needed" condition. } \\
\text { There were significant reductions in } \\
\text { positive test results for those without } \\
\text { mental health problems assigned to the } \\
\text { "as-needed" condition, but not to the } \\
\text { biweekly condition. However, there were no } \\
\text { overall differences either in drug tests or } \\
\text { self-reported drug use between groups } \\
\text { assigned to biweekly or "as-needed" } \\
\text { hearings. }\end{array}$ \\
\hline
\end{tabular}

All of the drug test results on substance use relapse were limited to those obtained when participants were still engaged in the drug court program. After drug court program participants exit the control of the criminal justice system, researchers must obtain participants' voluntary consent to obtain substance use relapse data, regardless of whether the data are selfreported or based upon urinalysis or other testing methods. ${ }^{2}$

\footnotetext{
${ }^{2}$ According to researchers, collecting these data can be expensive. Also, given likely differences between those who might volunteer and those who would decline, the collected data might have limited value.
} 
Appendix VI: Limited and Mixed Evidence on

Drug Court Programs' Impacts on Substance

Use Relapse

Evidence on Drug Court Programs' Impact on Substance Use Relapse Is Mixed
The results on substance use relapse are mixed. Four of the five drug court programs that used drug test results reported reductions in use. However, self-reported data on substance use relapse show contradictory results.

In both of the D.C. Superior Court dockets, prior to sentencing, drug court program participants had better drug test results than did defendants who had been randomly assigned to the control group. Similarly, in the Chester County Drug Court, within-program drug relapse was observed using drug test results. Drug court program participants had fewer positive urinalysis results than did a comparison group of eligible offenders who had been placed on probation in the 10 months prior to the implementation of the drug court program. These results indicate decreased relapse among participants despite the fact that drug court program participants were tested more frequently than were the members of the comparison group. However, in Maricopa County, there were no significant differences in the percentage of drug court participants and the combined control groups that tested positive.

One evaluation we reviewed provided limited evidence that judicial status hearings reduce within-program substance use for certain types of drug court program participants. This evaluation, an experiment in a drug court program in New Castle County, randomly assigned eligible drug court program defendants to one of two forms of judicial status hearing conditions: (1) biweekly, regularly scheduled status hearings or (2) status hearings scheduled on an as-needed basis. During the 14-week drug court program, participants with antisocial personality disorder (APD) and those who had prior drug treatment episodes had significantly lower levels of substance use - as measured by drug test results-when they were assigned to regularly scheduled biweekly judicial status hearings as compared with when they were assigned to status hearings on an asneeded basis. ${ }^{3}$

Four of the six programs with self-reported drug use results reported no significant reductions in use. For example, after sentencing, neither of the D.C. Superior Court dockets' participants reported lower rates of substance use. Alternatively, in two of the three Breaking the Cycle programs, participants reported lower rates of substance use than did

\footnotetext{
${ }^{3}$ Preliminary data from replication experiments confirmed the results of the original experiment, in that the researchers found evidence of the interaction between the mental health status of participants and biweekly status hearings.
} 
Appendix VI: Limited and Mixed Evidence on

Drug Court Programs' Impacts on Substance

Use Relapse

comparison group members. These differences in self-reported substance use persisted even after the researchers controlled for sample differences and selection. The use of self-reported data presents challenges related to underreporting that we have discussed in a prior report. ${ }^{4}$

${ }^{4}$ For more information, please see GAO, Drug Use Measurement: Strengths, Limitations and Recommendations for Improvement, GAO/PEMD-93-18 (Washington, D.C.: June 25, 1993). 


\section{Appendix VII: Evidence Is Mixed about the Factors That Predict Program Completion}

As discussed in appendix $\mathrm{V}$, participants who completed the drug court program (that is, graduates) had much lower recidivism rates than those who dropped out. Further, the recidivism rates for drug court program dropouts are comparable to the rates of comparison group members. Completion rates - an indicator of the extent to which participants successfully complete their drug court program requirements-for participants in selected programs we reviewed ranged from about 30 percent to about 70 percent. $^{1}$

In evaluations of 16 drug court programs in which completion was assessed, one factor - drug court program participants' compliance with program procedures - was consistently associated with program completion. These program procedures include attending treatment sessions, producing drug-free urinalysis test results, and appearing at status hearings. No other program factor, such as the severity of the sanction that would be imposed if participants failed to complete the program or the manner in which judges conducted status hearings, predicted participants' program completion. Several characteristics of the drug court program participants themselves were also associated with an increased likelihood of program completion. These characteristics, while not assessed in all of the programs, include lower levels of prior involvement in the criminal justice system, and age, as older participants were more likely to complete drug court programs than younger ones.

Program Completion Rates Vary
Completion rates ranged from 27 percent to 66 percent for 16 drug court programs included in evaluations that assessed program completion. These rates, while consistent with rates reported in other reviews of multiple drug court programs, are not directly comparable because drug court programs have different program completion requirements, the rates were measured over varying time periods, and study designs can affect the completion measures. Participants are not only required to attend treatment, but also to appear in court on a regular basis and follow other rules that are specific to the drug court program. These rules can involve, but are not limited to, policies on drug testing, case manager or probation officer visits, school or job attendance, support groups, and graduation

${ }^{1}$ Completion rates represent the individuals who completed or were favorably discharged from a drug court program as a percentage of the total number admitted and not still enrolled. 
requirements. Table 12 shows completion rates for the drug court programs whose evaluations assessed program completion.

\section{Table 12: Completion Rates for Selected Drug Court Programs Included in GAO's} Review

\begin{tabular}{lr}
\hline Drug court program & Completion rate \\
\hline Bakersfield Municipal Drug Court & $36 \%$ \\
\hline Bronx Treatment Court & 44 \\
\hline Brooklyn Treatment Court & 44 \\
\hline (Rempel and others, 2003) & 58 \\
\hline (Rempel and DeStefano, 2001) & 39 \\
\hline Broward County Drug Court & 29 \\
\hline (Schiff and Terry, 1997) & $52^{\mathrm{a}}$ \\
\hline (Senjo and Leip, 2001) & 48 \\
\hline Clark County Drug Court & 48 \\
\hline Creek County Drug Court & 45 \\
\hline Escambia County Drug Court Program & 49 \\
\hline (Peters and Murrin, 2000) & 29 \\
\hline (Peters, Haas, and Murrin, 1999) & 27 \\
\hline (Truitt and others, 2002) & $51^{\mathrm{a}}$ \\
\hline Jackson County Drug Court Program & 62 \\
\hline (Anspach and Ferguson, 2003) & 58 \\
\hline (Truitt and others, 2002) & 49 \\
\hline Multnomah County STOP Drug Diversion Program & 53 \\
\hline New Castle County Drug Court & 43 \\
\hline As-needed hearings & 66 \\
\hline Biweekly hearings & 62 \\
\hline Okaloosa County Drug Court & \\
\hline Orange County Drug Court Program & \\
\hline Queens Treatment Court & \\
\hline St. Mary Parish Drug Court & \\
\hline Suffolk County Drug Treatment Court & \\
\hline Syracuse Community Treatment Court & \\
\hline Source: GAO analysis of drug court program evaluations. & \\
\hline
\end{tabular}

aEvaluation reports "favorable" status, which includes defendants active in treatment plus those who graduated. 
As noted earlier, drug court programs vary in their specific program completion requirements. Similarly, programs may terminate defendants' program participation for a variety of reasons. Drug court program participants can be terminated from the program if they are arrested for a new offense, especially for felony offenses; if they regularly fail to appear at status hearings or treatment sessions; or if they repeatedly do not comply with program procedures. Consecutive positive drug test results do not always lead to program termination; in some programs, this could lead to a change in the treatment services provided or sanctions.

Program Completion Is Associated with Compliance with Program Procedures
Drug court participants' compliance with drug court procedures, such as appearing at treatment sessions and remaining drug-free during the program, was generally a strong predictor of program completion. The level of program compliance is typically indicated by the degree to which participants follow rules and procedures determined by the drug court program, attend required meetings and treatment sessions, and generally progress toward recovery. Given that program completion is related to compliance with drug court procedures, we sought to assess whether the evaluations included in our review provided conclusive evidence about specific aspects of compliance that were associated with program completion. For example, in some drug court programs greater levels of participation were associated with greater likelihood of completing the drug court program. Similarly, participants having more within-program arrests, more instances of warrants for failure to appear, and more positive drug tests were generally less likely to complete the program than those having fewer of these.

However, for some of the specific aspects of compliance, the findings were not consistent across drug court programs and in some cases they were even contradictory. For example, one evaluation of four drug court programs (Bakersfield, Creek County, Jackson County, and St. Mary's Parish) found an inconsistent relationship between drug test results and program completion across the four drug court programs. This cross-site evaluation assessed how various aspects of compliance predicted completion in each program using the same measures of compliance in each drug court program. In relation to the association between drug test results and completion, the evaluation found that in one program (Creek County) drug test results did not have a significant effect on completion. In another drug court program (St. Mary's Parish), drug court program participants that had no positive drug test results were more likely to complete the program than were participants who had comparatively "low" or "moderate" numbers of positive test results, whereas there were 
no differences in program completion between those participants who had comparatively "high" numbers of positive test results and those who had no positive test results. ${ }^{2}$ In the two remaining programs (Bakersfield and Jackson County), participants with positive test results in the low range actually had a higher likelihood of completing the program than participants with no positive test results, while in Jackson County, participants with positive test results in the high range were less likely than those with no positive test results to complete the program. This evaluation suggests that there may not be consistency across every drug court program in the relationship between drug test results and program completion.

Initial Engagement of Drug Court Participants
Some research studies indicate that drug court participants' first few weeks in treatment are predictive of success. Early engagement in the drug court program has been measured by whether participants attended treatment during the first few weeks after program entry and whether participants have fewer indications of noncompliance (such as failure to appear or warrants) during the first month of program participation.

One evaluation of five drug court programs in New York State assessed the role of participants' early engagement in the drug court program on their chances of completing the program. ${ }^{3}$ It found, consistently among the drug court programs, that early engagement by participants, measured by whether the participant absconded from program contact within 30 days of program entry significantly predicted program completion. Across the five New York drug court programs, participants that received warrants within 30 days of program entry were from about three to eight times more likely to fail to complete the drug court program than were participants who did not receive a warrant within 30 days of program entry. ${ }^{4}$

\footnotetext{
${ }^{2}$ The evaluation classified the percent of positive drug test results into four categories: (1) zero positive test results; (2) "low," where the percentage of test results that were positive ranged from 1 to 8 percent of drug tests; (3) "moderate," where the percentage of test results that were positive ranged from 9 to 28 percent of drug tests; and (4) "high," where the percentage of test results that were positive ranged from 29 to 100 percent.

${ }^{3}$ The drug court programs were in the Bronx, Brooklyn, Queens, Suffolk County, and Syracuse.

${ }^{4}$ As defined in the evaluation of these drug court programs, a judge issues a bench warrant when a defendant fails to make a scheduled court appearance. Bench warrants can also be issued if defendants fail to appear for scheduled appointments with case managers or treatment representatives.
} 
Further, in the Brooklyn Treatment Court, participants' compliance with drug court program procedures early in the program also contributed to participants' completing 90 days of drug treatment. Those participants who disappeared from contact, prompting the issuance of a police warrant, had lower chances of completing 90 days of treatment than those participants who did not. Additionally, those participants who attended at least 1 day of treatment within 30 days of entering the program also had greater chances of completing 90 days of treatment than those who did not attend at least 1 day of treatment within the first 30 days of entering the program.

Other aspects of compliance, such as treatment attendance during the entire program, appearance at status hearings, within-program arrests, and failure to appear, were generally but not consistently associated with completion. For example, the percentage of expected treatment sessions attended increased the likelihood of completion in five of seven drug court programs. ${ }^{5}$ On the other hand, in two of the four drug court programs in which they were measured, within-program arrests and failure to appear decreased the likelihood of completion but had no effect in the other two drug court programs. ${ }^{6}$ Alternatively, in both drug court programs (Multnomah and Clark Counties) in which the effects of within-program sanctions were assessed, an increase in the number of sanctions ordered led to a decrease in the likelihood of completion.

\section{Effects of Drug Court Programs' \\ Components on Program Completion Are Mixed}

In several drug court programs, the effects of various drug court program components were examined to determine the factors that predict program completion. Among the components that were examined were various consequences of program failure and the role of the judge and judicial status hearings. In a few drug court programs, efforts were made to examine the role of individual motivation to participate in drug court programs. In addition, evaluations of a few drug court programs examined the role of social factors in predicting program completion. Specifically,

\footnotetext{
${ }^{5}$ The five in which treatment attendance increased the chances of completion were (1) Bakersfield, (2) Clark County, (3) Creek County, (4) St. Mary's Parish, and (5) Multnomah, while the two in which it did not affect completion were Jackson County and Broward County.

${ }^{6}$ In the Bakersfield and Jackson County drug court programs, these effects were observed, but in the Creek County and St. Mary's Parish drug court programs, the effects were not observed.
} 
these evaluations assessed variables that measured individual's attachments to other individuals and social institutions.

Legal Consequences of Program Failure
Several drug court program evaluations in our review assessed the effects of different sanctions, or legal consequences of failure, on program completion. For example, if a drug court program participant fails to complete the program, he or she may be sentenced to a predetermined incarceration alternative. The results of these evaluations were mixed and not directly comparable. ${ }^{7}$ For example, in the Brooklyn Treatment Court, participants with a more serious treatment mandate - that is, those participants that faced longer jail or incarceration terms if they failed to comply with program requirements-were more likely to complete the drug court program than those with a less serious treatment mandate. The predetermined jail sentences for Brooklyn participants who failed to complete the program ranged from 6 months to $4 \frac{1}{2}$ years, depending on the severity of the charge (felony or misdemeanor) and prior criminal history (whether it was a first felony offense or not).

Alternatively, in the drug court program in Suffolk County, the length of the incarceration sentence faced by those who failed to complete the drug court program did not contribute to program completion. The predetermined sentence (minimum length of the most common prison alternative) in Suffolk County ranged from 6 months to 1 year. The researchers who conducted the evaluation did not provide an explanation for these differing effects. ${ }^{8}$

The judge has been described in the research as a key component of a drug court program. The presence of consistent judicial monitoring of participants is also described as a distinguishing component of drug court

\footnotetext{
${ }^{7}$ A number of variables are used to indicate the amount of legal coercion facing participants. These include the type and severity of charge leading participants to enter the drug court program, the length of the incarceration time participants face if they fail the drug court program (only in Suffolk), jail or prison alternatives (not used in Bronx, Suffolk, and Syracuse), the "treatment mandate," which is used in one program (Brooklyn) as a proxy for jail or prison alternative because there is a fairly uniform sentencing approach based on the treatment mandate.

${ }^{8}$ Rempel, M., and others, The New York State Adult Drug Court Evaluation: Policies, Participants, and Impacts. New York: Center for Court Innovation, 2003, p. 100.
} 
programs, compared with other court-based treatment programs, such as probation. Several evaluations in our review examined the effect of drug court judges on program completion. Each demonstrated that judges can play an important role in contributing to participants' program completion. However, the effect of the judge on program completion is difficult to distinguish from the requirement to attend judicial status hearings. For example, one evaluation of drug court program completion in Broward County attempted to assess the types of comments that judges made and the effect of these comments on program completion. Court monitoring comments made by judges that the researchers classified as supportive were found to contribute to program completion. ${ }^{9}$ On the other hand, in one evaluation of two drug court programs (Clark and Multnomah Counties), the number of appearances before the drug court judge was found to increase the likelihood of program completion.

A third evaluation (in New Castle County, Delaware) assessed the regularity of judicial status hearings on program completion. Participants were randomly assigned to one of two different forms of judicial status hearings: (1) biweekly hearings and (2) hearings on an as-needed basis, as determined by court officials. There were two main findings from this evaluation (that were also supported by the two replications of the experiment). First, there was no "direct" effect of the different status hearing schedules on program completion rates. Second, there was an interaction between client characteristics and program completion. Drug court program participants that either had prior treatment experiences or were diagnosed as having APD were more likely to complete the program when they were assigned to the regular biweekly status hearings as compared with when they were assigned to status hearings on an asneeded basis. Conversely participants who were not diagnosed as having APD or who had no prior treatment experiences were more likely to complete the program when they were assigned to status hearings on an as-needed basis, as compared with the biweekly condition.

The results from the New Castle County experiment show that the regularity of the schedule of status hearings can contribute to program completion for distinct subpopulations of drug court program participants

${ }^{9}$ Senjo, S. R., and L. A. Leip. "Testing and Developing Theory in Drug Court: A Four-Part Logit Model to Predict Program Completion," Criminal Justice Policy Review, vol. 12, no. 1, 2001, p. 82. 
and that there may not be a "one size fits all" approach to scheduling court appearances for all participants.

Participants Who
Were Older and Had
Less Criminal History
than Other
Participants Were
Most Likely to
Complete Programs

The evaluations of several drug court programs examined some of the attributes of drug court participants and how those factors were related to program completion. Attributes such as prior substance abuse treatment, prior criminal history, type of drug used, demographic characteristics, and employment and education were assessed. Prior criminal history, whether measured by the number of arrests or convictions prior to program entry, and age, as older were generally likely to complete their drug court programs than were younger participants to complete the program, were related to program completion.

The other attributes were generally found not to be significant predictors of completion, although among various minorities of drug court programs in which they were assessed, they were significant predictors of completion. For example, prior substance abuse treatment was a significant predictor of completion in three of seven drug court programs, but it was not significant in the other four drug court programs. Similarly, other attributes such as type of drug use, race or ethnicity, gender, or employment or education level were not observed to consistently predict completion.

The evaluations that assessed participants' attributes were correlationalthat is, they that examined the associations among these factors and the probability of program completion. Although not all of the evaluations included all of the same factors in their analyses, some general patterns about the correlates of program completion emerged. Attributes of drug court program participants that were associated with an increased likelihood of program completion include the following: (1) lower levels of prior criminal history; (2) substance use other than cocaine or heroin; (3) employment or school attendance at the time of program intake, along with higher levels of education; and (4) age, as older participants were more likely to complete the programs. ${ }^{10}$ One evaluation attempted to measure the effect of motivation and readiness for treatment on program completion. It found that those participants who were better able to

\footnotetext{
${ }^{10}$ However, not all of these factors consistently predicted program completion in all drug court programs in which they were examined.
} 
Appendix VII: Evidence Is Mixed about the

Factors That Predict Program Completion

recognize their problems, recognize external problems, and were ready for treatment, were more likely to complete the drug court program. 


\section{Appendix VIII: Evidence from Four Evaluations Indicates Drug Court Programs' Positive Net Benefits}

Four evaluations in our review included sufficient information about seven drug court programs' costs and benefits to estimate their net benefitsthat is, benefits less costs. ${ }^{1}$ All but one of the evaluations found that drug court programs were more expensive than conventional case processing. The costs to operate drug court programs above the costs of providing conventional case processing services ranged from about $\$ 750$ to about $\$ 8,500$ per participant. However, taking into account the drug court programs' benefits, especially the reduced costs of crime associated with reductions in recidivism, all four evaluations we reviewed reported net benefits ranging from about $\$ 1,000$ per participant to about $\$ 15,000$, mostly because of reduced victimization. Additionally, these benefits may underestimate drug court programs' true benefits because the evaluations did not include indirect benefits (such as reduced medical costs of treated participants).

Most Evaluations Found Drug Court Programs More Expensive than Conventional Case Processing
All but one of the evaluations we reviewed found drug court programs more expensive than conventional case processing. A combination of judicial supervision, monitoring, and treatment services that drug court programs typically provide to their participants-services in addition to those provided to offenders who are processed with conventional procedures receive-result in additional expense to criminal justice agencies. Table 13 shows the net costs of drug court programs-costs above normal court costs-including supervision, monitoring, and treatment, ranging from somewhat less than $\$ 800$ to about $\$ 8,700$ per participant.

\footnotetext{
${ }^{1}$ Appendix III provides more information about our review of drug court program evaluations that presented cost data and the criteria we used to assess them.
} 
Table 13: Reported Costs per Drug Court Program Participant in Four Evaluations

\begin{tabular}{lr}
\hline Drug court program & Costs above normal costs \\
\hline D.C. Superior Court Drug Intervention Program & \\
\hline Treatment docket & $\$ 8,708$ \\
\hline Sanctions docket & 3,248 \\
\hline Washington State Drug Court Program & 3,892 \\
\hline Breaking the Cycle Program ${ }^{a}$ & 1,461 \\
\hline Tacoma, Wash. & 1,133 \\
\hline Jacksonville, Fla. & 767 \\
\hline Birmingham, Ala. & $(1,442)$ \\
\hline Multnomah County (Ore.) STOP Program
\end{tabular}

Source: Drug court program evaluations

${ }^{\text {a } A c c o r d i n g ~ t o ~ t h e ~ p r i n c i p a l ~ r e s e a r c h e r ~ o f ~ t h e ~ e v a l u a t i o n, ~ t h e ~ B r e a k i n g ~ t h e ~ C y c l e ~ p r o g r a m ~ i s ~ t e c h n i c a l l y ~}$ not considered to be a drug court program. However, we included the program in our review because it incorporates several of the basic drug court program components, such as drug testing and access to treatment services.

The Multnomah County drug court program cost about $\$ 1,400$ less than normal court procedures. Rather than relying on administrative records and budgets, the program's evaluation used a methodology that closely followed participants through treatment and court adjudication. It calculated the amount of time that each drug court participant and comparison group participant spent in different activities, such as treatment and court hearings. The evaluation found that the judge spent less time with offenders in the drug court program than in normal court processing and that this led to the estimated decreased costs.

\section{Drug Court Programs' Net Benefits Derived from Reductions in Recidivism}

The monetary benefits of reduced recidivism can be placed in two categories: (1) reduced future expenditure by criminal justice agencies and (2) reduced future victimization. Any arrest is a cost to a number of criminal justice agencies, including police, prosecutors, courts, corrections departments, and probation agencies. Reducing arrests by reducing recidivism would benefit these agencies. ${ }^{2}$ The justice system's benefits in the seven drug court programs we reviewed ranged from none to about $\$ 3,800$ per participant. Some of the range is due to methodological differences among the evaluations, but some may be due

\footnotetext{
${ }^{2} \mathrm{~A}$ reduction in arrests would result in a benefit to the taxpaying members of society, since taxpayers fund the criminal justice agencies.
} 
to differences among the communities served by the courts. A reduction in recidivism also benefits people who might otherwise be victimized. The costs to potential victims of crime that are thus avoided include direct monetary costs, such as the value of property that is not stolen and expenses for health care that are not incurred, and quality-of-life costs, such as costs for pain and suffering that are not experienced. Benefits to potential victims reported in the evaluations we reviewed ranged from about $\$ 500$ to $\$ 24,000$ per participant.

The evaluations we reviewed monetized the benefits from averted crime inconsistently, but the differences in method do not explain the range of benefits. For example, excluding the cost of pain and suffering from victimizations that do not occur underestimates the true cost of crime. However, the two evaluations that did not include these costs-D.C. Superior Court and Breaking the Cycle-found the highest and lowest per participant dollar values of reduced recidivism, at $\$ 24,000$ and $\$ 500$, respectively.

\section{All Seven Drug Court Programs Reported Positive Net Benefits}

Although six of the seven drug court programs were more costly than conventional case processing, the monetary value of the benefits from reduced recidivism - to the justice system and potential victims-was greater than the costs, producing positive net benefits in all seven programs. The net benefits of the seven drug court programs we reviewed ranged from about $\$ 1,000$ to about $\$ 15,000$ per participant. Table 14 presents benefits to the justice system and to potential victims, the net costs of the programs (costs of the drug programs above conventional case processing), and net benefits, or benefits minus net costs. 
Table 14: Net Benefits per Participant in Seven Drug Court Programs

\begin{tabular}{|c|c|c|c|c|c|}
\hline \multirow[b]{2}{*}{ Drug court program } & \multicolumn{2}{|c|}{ Benefits } & \multirow[b]{2}{*}{$\begin{array}{r}\text { Costs (net drug court } \\
\text { program costs) }\end{array}$} & \multicolumn{2}{|c|}{ Net benefits (benefits less costs) } \\
\hline & $\begin{array}{l}\text { Justice } \\
\text { system }\end{array}$ & $\begin{array}{r}\text { Avoided } \\
\text { potential victim }\end{array}$ & & $\begin{array}{l}\text { Justice } \\
\text { system }\end{array}$ & $\begin{array}{r}\text { Justice system } \\
\text { plus avoided } \\
\text { potential victims }\end{array}$ \\
\hline \multicolumn{6}{|c|}{ D.C. Superior Court Drug Intervention Program } \\
\hline Treatment docket $^{a}$ & & $\$ 24,030^{b}$ & $\$ 8,708$ & & $\$ 15,322$ \\
\hline Sanctions docket & $\$ 19^{c}$ & $6,203^{\mathrm{b}}$ & 3,248 & $(\$ 3,230)$ & 2,973 \\
\hline \multicolumn{6}{|c|}{ Breaking the Cycle Program } \\
\hline Tacoma, Wash. & $394^{\mathrm{c}}$ & $7,324^{\mathrm{b}}$ & 1,461 & $(1,067)$ & 6,257 \\
\hline Jacksonville, Fla. & $0^{c}$ & $2,900^{b}$ & 1,133 & $(1,133)$ & 1,767 \\
\hline Birmingham, Ala. & $1,320^{\circ}$ & $479^{b}$ & 767 & 553 & 1,032 \\
\hline $\begin{array}{l}\text { Multnomah County } \\
\text { (Ore.) STOP Program }\end{array}$ & 2,329 & 1,301 & $(1,442)$ & 3,771 & 5,072 \\
\hline $\begin{array}{l}\text { Washington State Drug } \\
\text { Court Program }\end{array}$ & 3,759 & 3,020 & 3,891 & (132) & 2,888 \\
\hline
\end{tabular}

Source: GAO analysis of drug court program evaluations' reported costs and benefits.

${ }^{a}$ The D.C. Superior Court Drug Intervention Program evaluation did not draw conclusions about the net benefits of the treatment docket because of inconsistencies between self-reported crime and official arrest records.

${ }^{b}$ Benefits to potential victims were derived from survey data and do not include the cost of pain and suffering.

${ }^{c}$ Benefits to the justice system were determined by official records of arrest.

However, as shown in the last two columns of table 14, the financial cost savings due to reductions in recidivism for the criminal justice agencies were not always positive. Positive financial cost savings for the criminal justice agencies were indicated for only two programs-Breaking the Cycle Program in Birmingham and the drug court program in Multnomah County.

\section{Net Benefits May Underestimate the Programs' True Benefits}

None of the evaluations included indirect, or secondary, benefits to society derived from a reduction in participants' substance abuse. Indirect benefits might include costs avoided because treated drug addicts did not use medical services that would otherwise have been required. After successful drug treatment, such individuals might have fewer periods of unemployment and might be more productive, earning higher wages. To the extent that they pay higher taxes as a result, these are benefits to taxpaying members of society. While these benefits are difficult to quantify in assessing a drug court program, their absence suggests that reported net benefits are understated. 


\section{Appendix IX: GAO Contacts and Staff Acknowledgments}

GAO Contacts

Acknowledgments
Laurie E. Ekstrand, (202) 512-8777

William J. Sabol, (202) 512-3464
In addition to those named above, Mary Catherine Hult, David P. Alexander, Michele C. Fejfar, Benjamin A. Bolitzer, Harold J. Brumm, Jr., Wayne A. Ekblad, Ann H. Finley, Ronald La Due Lake, Jean L. McSween, Albert Schmidt, Barry J. Seltser, Douglas M. Sloane, Shana B. Wallace, and Kathryn G. Young made key contributions to this report. 


\section{Bibliography}

Anspach, D. F., and A. S. Ferguson. Assessing the Efficacy of Treatment Modalities in the Context of Adult Drug Courts: Final Report. Portland, Maine: University of Southern Maine, Department of Sociology, 2003.

Aos, S., P. Phipps, R. Barnoski, and R. Lieb. The Comparative Costs and Benefits of Programs to Reduce Crime, A Review of National Research Findings with Implications for Washington State. Olympia, Wash.: Washington State Institute for Public Policy, May 1999.

Banks, D. and D. C. Gottfredson. "The Effects of Drug Treatment and Supervision on Time to Rearrest among Drug Treatment Court Participants." Journal of Drug Issues, vol. 33, no. 2 (2003): 385-414.

Barnoski, R., and S. Aos. Washington State's Drug Courts for Adult Defendants: Outcome Evaluation and Cost-Benefit Analysis. Olympia, Wash.: Washington State Institute for Public Policy, 2003.

Belenko, S. Research on Drug Courts: A Critical Review 2001 Update. The National Center on Addiction and Substance Abuse at Columbia University, June 2001.

Breckenridge, J. F., L. T. Winfree, J. R. Maupin, and D. L. Clason. "Drunk Drivers, DWI 'Drug Court' Treatment, and Recidivism: Who Fails?” Justice Research and Policy, vol. 2, no. 1 (2000): 87-105.

Brewster, M. P. "An Evaluation of the Chester County (PA) Drug Court Program.” Journal of Drug Issues, vol. 31, no. 1 (2001): 177-206.

Carey, S., and M. Finigan. A Detailed Cost Analysis in a Mature Drug Court Setting: A Cost-Benefit Evaluation of the Multnomah County Drug Court. Portland, Ore.: Northwest Professional Consortium, July 2003.

Craddock, A. North Carolina Drug Treatment Court Evaluation: Final Report. Washington, D.C.: U.S. Department of Justice, Office of Justice Programs, Drug Court Program Office, 2002.

Croxton, F. E., D. J. Cowden, and S. Klein. Applied General Statistics, 3rd edition. (Englewood Cliffs, N.J.: Prentice-Hall, 1967).

Deschenes, E. P., L. Cresswell, V. Emami, K. Moreno, Z. Klein, and C. Condon. Success of Drug Courts: Process and Outcome Evaluations in Orange County, Califormia, Final Report. Submitted to the Superior Court of Orange County, California, September 20, 2001. 
Deschenes, E. P., I. Imam, T. L. Foster, L. Diaz, V. Moreno, L. Patascil, D. Ward, and C. Condon. Evaluation of Orange County Drug Courts for Orange County Superior Courts. Richmond, Calif.: The Center for Applied Local Research, 1999.

Deschenes, E. P., I. Imam, E. Castellonos, T. L. Foster, C. Ha, D. Ward, C. Coley, and K. Michaels. Evaluation of Los Angeles County Drug Courts. Richmond, Calif.: The Center for Applied Local Research, 2000.

Deschenes, E. P., S. Turner, P. Greenwood, and J. Chiesa. An Experimental Evaluation of Drug Testing and Treatment Interventions for Probationers in Maricopa County, Arizona. Santa Monica, Calif.: RAND, July 1996.

Festinger, D. S., D. B. Marlowe, P. A. Lee, K. C. Kirby, G. Bovasso, and A. T. McLellan. "Status Hearings in Drug Court: When More Is Less and Less Is More." Drug and Alcohol Dependence, vol. 68 (2002): 151-157.

Fielding, J. E., G. Tye, P. L. Ogawa, I. J. Imam, and A. M. Long. "Los Angeles County Drug Court Programs: Initial Results." Journal of Substance Abuse Treatment, vol. 23 (2002): 217-224.

Finigan, M. An Outcome Program Evaluation of the Multnomah County S.T.O.P. Drug Diversion Program. Portland, Ore.: Northwest Professional Consortium, 1998.

Goldkamp, J. S., M. D. White, and J. B. Robinson. "Do Drug Courts Work? Getting Inside the Drug Court Black Box." Journal of Drug Issues, vol. 31, no. 1 (2001): 27-72.

Goldkamp, J. S., M. D. White, and J. B. Robinson. From Whether to How Drug Courts Work: Retrospective Evaluation of Drug Courts in Clark County (Las Vegas) and Multnomah County (Portland)—Phase II Report from the National Evaluation of Drug Courts. Philadelphia, Pa.: Crime and Justice Research Institute, 2001.

Goldkamp, J. S., M. D. White, and J. B. Robinson. Retrospective Evaluation of Two Pioneering Drug Courts: Phase I Findings from Clark County, Nevada, and Multnomah County, Oregon: An Interim Report of the National Evaluation of Drug Courts. Philadelphia, Pa.: Crime and Justice Research Institute, 2000. 
Gottfredson, D. C., S. S. Najaka, and B. Kearley. "Effectiveness of Drug Treatment Courts: Evidence from a Randomized Trial." Criminology and Public Policy, vol. 2, no. 2 (2003): 171-196.

Gottfredson, D. C., and M.L. Exum. "The Baltimore City Drug Treatment Court: One-Year Results from a Randomized Study." Journal of Research in Crime and Delinquency, vol. 39, no. 3 (2002): 337-356.

Harrell, A., S. Cavanagh, and J. Roman. Final Report: Findings from the Evaluation of the D.C. Superior Court Drug Intervention Program. Washington D.C.: Urban Institute, 1998.

Harrell, A. and J. Roman. "Reducing Drug Use and Crime among Offenders: The Impact of Graduated Sanctions." Journal of Drug Issues, vol. 31, no. 1 (2001): 207-232.

Harrell, A., O. Mitchell, J. Merrill, and D. Marlowe. Evaluation of Breaking the Cycle. Washington D.C.: The Urban Institute, February 2003.

Harrell, A., O. Mitchell, A. Hirst, D. Marlowe, and J. Merrill. "Breaking the Cycle of Drugs and Crime: Findings from the Birmingham BTC Demonstration." Criminology and Public Policy, vol. 1, no. 2 (2002): 189216.

Listwan, S. J., J. L. Sundt, A. M. Holsinger, and E. J. Latessa. "Effect of Drug Court Programming on Recidivism: The Cincinnati Experience." Crime \& Delinquency, vol. 49, no. 3 (2003): 389-441.

Logan, T. K, W. Hoyt, and C. Leukefeld. Kentucky Drug Court Outcome Evaluation: Behavior, Costs, and Avoided Costs to Society. Lexington, Ky.: Center on Drug and Alcohol Research, University of Kentucky, October 2001.

Marlowe, D. B., D. S. Festinger, and P. A. Lee. "The Judge Is a Key Component of Drug Court." National Drug Court Institute Review, vol. IV, no. 2 (2004): 1-34.

Marlowe, D. B., D. S. Festinger, P. A. Lee, M. Schepise, J. E. R. Hazzard, J. C. Merrill, F. D. Mulvaney, and A. T. McLellan. "Are Judicial Status Hearings a Key Component of Drug Court? During-Treatment Data from a Randomized Trial." Criminal Justice and Behavior, vol. 30, no. 2 (2003): 141-162. 
Martin, T. J., C. Spohn, R. K. Piper, and E. Frenzel-Davis. Phase III Douglas County Drug Court Evaluation: Final Report. Omaha, Neb.: Institute for Social and Economic Development, May 2001.

Miethe, T. D., H. Lu, and E. Reese. "Reintegrative Shaming and Recidivism Risks in Drug Court: Explanations for Some Unexpected Findings." Crime \& Delinquency, vol. 46, no. 4 (2000): 522-541.

Office of Management and Budget Circular A-94, "Guidelines and Discount Rates for Benefit-Cost Analysis of Federal Programs." (October 29, 1992, revised January 29, 2002)

Peters, R. H., and M. R. Murrin. "Effectiveness of Treatment-Based Drug Courts in Reducing Criminal Recidivism." Criminal Justice and Behavior, vol. 27 , no. 1 (2000): 72-96.

Peters, R. H., and M. R. Murrin. Evaluation of Treatment-Based Drug Courts in Florida's First Judicial Circuit. Tampa, Fla.: Department of Mental Health Law and Policy, Louis de la Parte Florida Mental Health Institute, University of South Florida, 1998.

Peters, R. H., A. L. Haas, and M. R. Murrin. "Predictors of Retention and Arrest in Drug Courts." National Drug Court Institute Review, vol. II, no. I (1999): 30-57.

Rempel, M., and C. DeStefano. "Predictors of Engagement in CourtMandated Treatment: Findings from the Brooklyn Treatment Court, 19962000." Journal of Offender Rehabilitation, vol. 33, no. 4 (2001): 87-124.

Rempel, M., D. Fox-Kralstein, A. Cissner, R. Cohen, M. Labriola, D. Farole, A. Bader, and M. Magnani. The New York State Adult Drug Court Evaluation: Policies, Participants, and Impacts. New York: Center for Court Innovation, 2003.

Roman, J., and A. Harrell. "Assessing the Costs and Benefits Accruing to the Public from a Graduated Sanctions Program for Drug-Using Defendants." Law and Policy, vol. 23, no. 2 (2001): 237-268.

Roman, J., J. Woodard, A. Harrell, and S. Riggs. Final Report: $A$ Methodology for Measuring Costs and Benefits of Court-Based Drug Intervention Programs Using Findings from Experimental and Quasiexperimental Evaluations. Washington D.C.: The Urban Institute, December 1998. 
Schiff, M., and W. C. Terry, III. "Predicting Graduation from Broward County's Dedicated Drug Treatment Court." The Justice System Journal, vol. 19, no. 3 (1997): 291-310.

Senjo, S. R., and L. A. Leip. "Testing and Developing Theory in Drug Court: A Four-Part Logit Model to Predict Program Completion." Criminal Justice Policy Review, vol. 12, no. 1(2001): 66-87.

Spohn, C., R. K. Piper, T. Martin, and E. D. Frenzel. "Drug Courts and Recidivism: The Results of an Evaluation Using Two Comparison Groups and Multiple Indicators of Recidivism." Journal of Drug Issues, vol. 31, no. 1 (2001): 149-176.

Stokey, E., and Zeckhauser. A Primer for Policy Analysis. (New York: W.W. Norton and Company, 1978).

Truitt, L., W. M. Rhodes, N. G. Hoffman, A. M. Seeherman, S. K. Jalbert, M. Kane, C. P. Bacani, K. M. Carrigan, and P. Finn. Evaluating Treatment Drug Courts in Kansas City, Missouri and Pensacola, Florida: Final Reports for Phase I and Phase II. Cambridge, Mass.: Abt Associates Inc., 2002.

Turner, S., P. Greenwood, T. Fain, and E. Deschenes. "Perceptions of Drug Court: How Offenders View Ease of Program Completion, Strengths and Weaknesses, and the Impact on Their Lives." National Drug Court Institute Review, vol. II, no. 1(1999): 58-81.

Wilson, D. B., O. Mitchell, and D. L. MacKenzie. "A Systematic Review of Drug Court Effects on Recidivism.” Forthcoming.

Wolfe, E., J. Guydish, and J. Termondt. "A Drug Court Outcome Evaluation Comparing Arrests in a Two Year Follow-Up Period." Journal of Drug Issues, vol. 2, no. 4 (2002): 1155-1172. 


\section{GAO’s Mission}

The Government Accountability Office, the audit, evaluation and investigative arm of Congress, exists to support Congress in meeting its constitutional responsibilities and to help improve the performance and accountability of the federal government for the American people. GAO examines the use of public funds; evaluates federal programs and policies; and provides analyses, recommendations, and other assistance to help Congress make informed oversight, policy, and funding decisions. GAO's commitment to good government is reflected in its core values of accountability, integrity, and reliability.

\section{Obtaining Copies of GAO Reports and Testimony}

The fastest and easiest way to obtain copies of GAO documents at no cost is through GAO's Web site (www.gao.gov). Each weekday, GAO posts newly released reports, testimony, and correspondence on its Web site. To have GAO e-mail you a list of newly posted products every afternoon, go to www.gao.gov and select "Subscribe to Updates."

\section{Order by Mail or Phone}

The first copy of each printed report is free. Additional copies are $\$ 2$ each. A check or money order should be made out to the Superintendent of Documents. GAO also accepts VISA and Mastercard. Orders for 100 or more copies mailed to a single address are discounted 25 percent. Orders should be sent to:

U.S. Government Accountability Office

441 G Street NW, Room LM

Washington, D.C. 20548

To order by Phone: Voice: (202) 512-6000

TDD: (202) 512-2537

Fax: (202) 512-6061

\section{To Report Fraud, Waste, and Abuse in Federal Programs}

\section{Contact:}

Web site: www.gao.gov/fraudnet/fraudnet.htm

E-mail: fraudnet@gao.gov

Automated answering system: (800) 424-5454 or (202) 512-7470

\section{Congressional Relations}

Gloria Jarmon, Managing Director, JarmonG@gao.gov (202) 512-4400 U.S. Government Accountability Office, 441 G Street NW, Room 7125 Washington, D.C. 20548

\section{Public Affairs}

Paul Anderson, Managing Director, AndersonP1@gao.gov (202) 512-4800

U.S. Government Accountability Office, 441 G Street NW, Room 7149 Washington, D.C. 20548 